\title{
COMPARISON OF FRACTURE METHODOLOGIES FOR FLAW STABILITY ANALYSIS FOR HIGH LEVEL WASTE STORAGE TANKS (U)
}

P. S. Lam

\author{
Savannah River Technology Center \\ Strategic Materials Technology Department \\ Materials Technology Section
}

Publication Date: November 2000

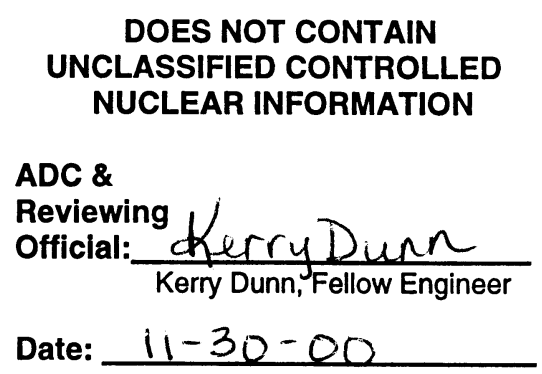

Patent Status

This internal management report is being transmitted

without DOE patent clearance, and no further

dissemination or publication shall be made of the report

without prior approval of the DOE-SR patent counsel.

\section{Westinghouse Savannah River Company Savannah River Site Aiken, SC 29808}

This document was prepared in connection with work done under Contract No. DE-AC09-96SR18500 with the U. S. Department of Energy 
This document was prepared in conjunction with work accomplished under Contract No.

DE-AC09-96SR18500 with the U.S. Department of Energy.

\section{DISCLAIMER}

This report was prepared as an account of work sponsored by an agency of the United States Government. Neither the United States Government nor any agency thereof, nor any of their employees, makes any warranty, express or implied, or assumes any legal liability or responsibility for the accuracy, completeness, or usefulness of any information, apparatus, product or process disclosed, or represents that its use would not infringe privately owned rights. Reference herein to any specific commercial product, process or service by trade name, trademark, manufacturer, or otherwise does not necessarily constitute or imply its endorsement, recommendation, or favoring by the United States Government or any agency

thereof. The views and opinions of authors expressed herein do not necessarily state or reflect those of the United States Government or any agency thereof.

This report has been reproduced directly from the best available copy.

Available for sale to the public, in paper, from: U.S. Department of Commerce, National Technical Information Service, 5285 Port Royal Road, Springfield, VA 22161, phone: (800)

553-6847, fax: (703) 605-6900, email: orders@ntis.fedworld.gov online ordering: http://www.ntis.gov/ordering.htm

Available electronically at http://www.doe.gov/bridge

Available for a processing fee to U.S. Department of Energy and its contractors, in paper, from: U.S. Department of Energy, Office of Scientific and Technical Information, P.O. Box 62, Oak Ridge, TN 37831-0062, phone: (865 ) 576-8401, fax: (865) 576-5728, email: reports@ adonis.osti.gov 
DOCUMENT: WSRC-TR-2000-00478

TITLE: $\quad$ Comparison of Fracture Methodologies for Flaw Stability Analysis for High Level Waste Storage Tanks (U)

APPROVALS

P.SL Lam

P. S. Lam, Author Materials Applications \& Process Technology Group SRTC-Materials Technology Section

lentil Shan

K. H. Subramanian, Technical Reviewer Materials Applications \& Process Technology Group SRTC-Materials Technology Section

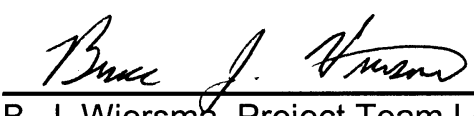

B. J. Wiersma, Project Team Lead Tank Life Management Program SRTC-Materials Technology Section
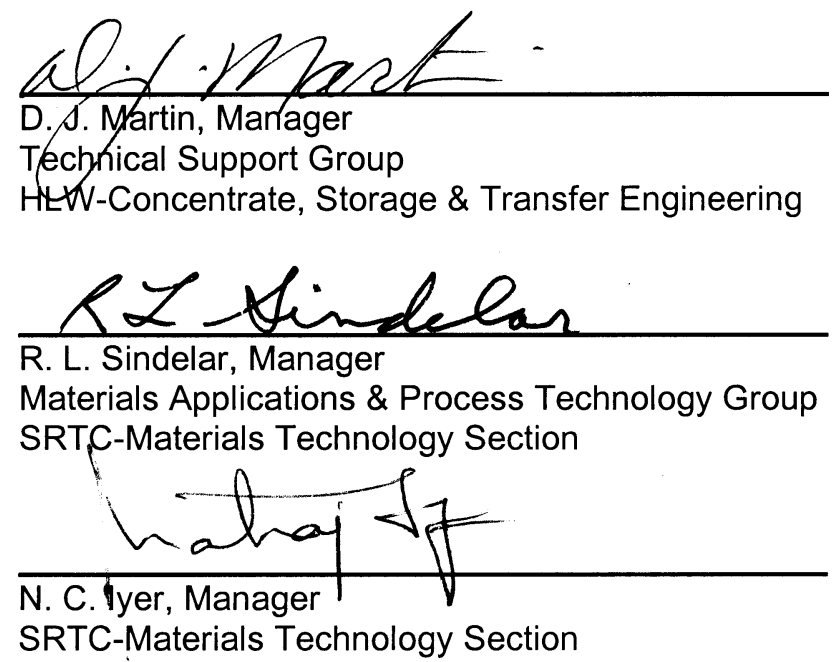

Date: $11 / 29 / 2000$

Date: $11 / 29 / 2000$

Date: $1 / 24 / 01$

Date: $1 / 3 \cdot / 01$

Date: $11 / 29 / 00$

Date: $1 / 3 / / 01$ 
(Blank Page) 
WSRC-TR-2000-00478

Table of Contents

$\underline{\text { Section }}$

$\underline{\text { Page }}$

$1.0 \quad$ EXECUTIVE SUMMARY ....................................................... 1

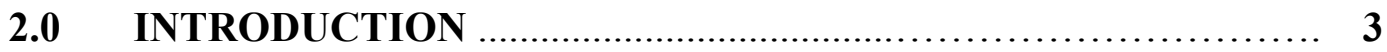

3.0 MATERIAL PROPERTIES.............................................. 4

4.0 J-INTEGRAL TEARING MODULUS METHODOLOGY ....... 6

4.1 Flaw Stability ........................................... 6

4.2 Cut-off for J-controlled Crack Growth ..................... 7

4.3 J-Integral Estimation Method ......................... 8

4.4 Curvature Corrections ................................ 11

4.5 General Procedure for Combining J-integral Contributions . 12

4.6 Results of J-T Approach ............................ 13

5.0 FAILURE ASSESSMENT DIAGRAMS ..................... 13

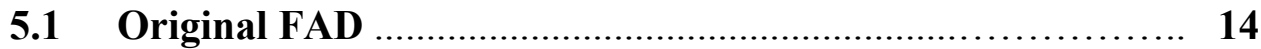

$5.2 \quad$ J-Based FAD .............................................. 15

5.3 API Recommended FAD Approaches ................... 15

5.4 Determination of Instability Crack Length Based on FAD ... 16

6.0 COMPARISON OF THE INSTABILITY CRACK LENGTHS ... 18

7.0 FINITE ELEMENT VALIDATION ....................... 23

7.1 Finite Element Modeling .............................. 24

7.2 Accuracy of the CCP Solution ......................... 25

7.3 Comparison of the Instability Crack Lengths .............. 27

7.4 Finite-Element-Based Failure Assessment Diagrams ........ 29

7.5 Software QA Control .............................. 31

8.0 FRACTURE METHODOLOGY REFINEMENT ............... 31

9.0 DISCUSSION AND CONCLUDING REMARKS .............. 32

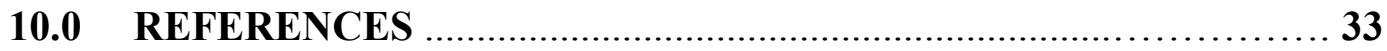


WSRC-TR-2000-00478

Table of Contents (Continued)

\section{LIST OF TABLES}

Table Number

\section{$\underline{\text { Page }}$}

1 Calculated Instability Crack Lengths for Type I Tanks ............. 1

2 Calculated Instability Crack Lengths for Type II Tanks ............. 1

3 Instability Crack Lengths for Type I Tank Geometry (inches) ...... 19

4 Instability Crack Length for Type II Tank Geometry (inches) ...... 19

5 Instability Crack Lengths based on Various Fracture

Methodologies (Type I Tank) 
WSRC-TR-2000-00478

Table of Contents (Continued)

\section{LIST OF FIGURES}

Figure Number

Page

1 Stress-Strain Curve of A285 E400 Steel ................................ 5

2 J-R Curve of A285 E400 Steel ................................ 5

3 Determination of Instability Crack Length with J-T Methodology ... 7

4 Extrapolation of Material J-T Curve to Intersect Applied J-T Curve 7

5 Typical J-T Curves for Determining Instability Crack Length ....... 8

6 Correspondence between an Axial Crack and a Center-Cracked Panel ....................................................... 9

7 Instability Crack Lengths Determined with J-T Methodology ....... 13

8 API 579 Recommended Failure Assessment Diagrams ............... 16

9 Determination of Instability Crack Length using FAD Approach ... 17

10 FAD Approach Utilizing J-R Curve Data .......................... 18

11 Comparison of Predicted Instability Crack Length with $\mathbf{J}_{\text {crit }}=\mathbf{J}_{\text {IC }}$ for Type I Tanks ........................................ 20

12 Comparison of Predicted Instability Crack Length with $\mathbf{J}_{\text {crit }}=\mathbf{J}_{3 \mathrm{~mm}}$ for Type I Tanks ............................................. 20

13 Comparison of Predicted Instability Crack Length with $\mathbf{J}_{\text {crit }}=\mathbf{J}_{\mathrm{IC}}$ for Type II Tanks ........................................... 21

14 Comparison of Predicted Instability Crack Length with $\mathbf{J}_{\text {crit }}=\mathbf{J}_{3 \mathrm{~mm}}$ for Type II Tanks ......................................... 21

15 Comparison of Predicted Instability Crack Lengths from J-T and FAD for Given $J_{\text {crit }}$ in Type $I$ Tanks ......................... 22

16 Comparison of Predicted Instability Crack Lengths from J-T and FAD for Given $J_{\text {crit }}$ in Type II Tanks ........................ 23

17 Finite Element Mesh for Type I Waste Tank Containing an Axial Crack ............................................. 24

18 Near Crack Tip Mesh Design and a Typical Deformed Shape ........ 25

19 Comparison of the Elastic Portion of the J-integral Solutions ........ 26

20 Comparison of the Solutions for Total J-integral .................... 27

21 Type I Tank Instability Crack Lengths Resulted from Various Fracture Methodologies when $\mathbf{J}_{\text {crit }}=\mathbf{J}_{\text {IC }} \ldots \ldots \ldots \ldots \ldots . .28$

22 Type I Tank Instability Crack Lengths Resulted from Various Fracture Methodologies when $\mathbf{J}_{\text {crit }}=\mathbf{J}_{3 \mathrm{~mm}} \ldots \ldots \ldots \ldots \ldots .29$

23 Crack Length-Dependent Reference Loads for Type I Tank with an Axial Flaw ................................................... 30

24 Finite-Element-Based Failure Assessment Diagrams ............... 31 
WSRC-TR-2000-00478

November 2000

page iv

(Blank Page) 


\subsection{EXECUTIVE SUMMARY}

Fracture mechanics methodologies for flaw stability analysis for Type I and II waste tanks were compared in terms of the maximum stable through-wall flaw sizes or "instability lengths." The comparison was made at a full range of remote stress loading states $\left(\sigma_{\text {appl }}\right)$ at a specific set of mechanical properties of A285 steel and with the Type I and II tank configurations. The two general methodologies, the J-integral-tearing modulus (J-T) and the failure assessment diagram (FAD), and their specific estimation schemes were evaluated. The results of the comparison are shown in the tables below.

Table 1. Calculated Instability Crack Lengths for Type I Tanks

\begin{tabular}{|c|c|c|c|c|c|c|c|c|c|c|c|c|}
\hline \multirow{5}{*}{$\sigma_{\text {appl }}$} & \multicolumn{12}{|c|}{ Type I Tank Instability Crack Lengths (inches) } \\
\hline & \multicolumn{6}{|c|}{$\mathrm{J}_{\text {crit }}=\mathrm{J}_{\mathrm{IC}}$} & \multicolumn{6}{|c|}{$\mathrm{J}_{\text {crit }}=\mathrm{J}_{3 \mathrm{~mm}}$} \\
\hline & J-T & J-T & $\mathrm{J}-\mathrm{T}$ & FAD & FAD & FAD & $\mathrm{J}-\mathrm{T}$ & J-T & J-T & FAD & FAD & FAD \\
\hline & CCP & FEA & FEA & API & $\sigma-\varepsilon$ & R-O & CCP & FEA & FEA & API & $\sigma-\varepsilon$ & $\mathrm{R}-\mathrm{O}$ \\
\hline & $\mathrm{R}-\mathrm{O}$ & R-O & $\sigma-\varepsilon$ & & & & $\mathrm{R}-\mathrm{O}$ & $\mathrm{R}-\mathrm{O}$ & $\sigma-\varepsilon$ & & & \\
\hline $6 \mathrm{ksi}$ & 74.0 & 67.0 & 71.0 & 66.4 & 68.0 & 61.8 & 118.0 & 110. & 114. & 104. & 110. & 96.0 \\
\hline $12 \mathrm{ksi}$ & 39.7 & 32.8 & 38.0 & 33.0 & 35.0 & 29.0 & 64.2 & 47.5 & 56.8 & 49.6 & 55.0 & 43.2 \\
\hline $18 \mathrm{ksi}$ & 23.1 & 19.0 & 24.8 & 20.2 & 22.0 & 17.0 & 40.0 & 30.1 & 36.9 & 29.4 & 32.0 & 25.8 \\
\hline $24 \mathrm{ksi}$ & 11.4 & 10.0 & 16.7 & 12.8 & 15.0 & 10.2 & 23.8 & 19.1 & 24.4 & 18.8 & 18.6 & 16.8 \\
\hline $30 \mathrm{ksi}$ & 4.6 & 4.6 & 10.0 & 7.4 & 8.8 & 5.8 & 12.4 & 10.8 & 16.3 & 11.8 & 8.6 & 10.8 \\
\hline $36 \mathrm{ksi}$ & 1.8 & 4.0 & 7.4 & 3.6 & 2.2 & 3.0 & 5.6 & 6.4 & 6.7 & 6.6 & 5.8 & 6.8 \\
\hline
\end{tabular}

Table 2. Calculated Instability Crack Lengths for Type II Tanks

\begin{tabular}{|c|c|c|c|c|c|c|c|c|}
\hline & \multicolumn{6}{|c|}{ Type II Tank Instability Crack Lengths (inches) } \\
\hline \multirow{3}{*}{$\sigma_{\text {appl }}$} & \multicolumn{4}{|c|}{$\mathrm{J}_{\text {crit }}=\mathrm{J}_{\text {IC }}$} & \multicolumn{5}{c|}{$\mathrm{J}_{\text {crit }}=\mathrm{J}_{3 \mathrm{~mm}}$} \\
\cline { 2 - 10 } & $\begin{array}{c}\text { J-T } \\
\text { CCP } \\
\text { R-O }\end{array}$ & $\begin{array}{c}\text { FAD: } \\
\text { API }\end{array}$ & $\begin{array}{c}\text { FAD: } \\
\sigma-\varepsilon\end{array}$ & $\begin{array}{c}\text { FAD: } \\
\text { R-O }\end{array}$ & $\begin{array}{c}\text { J-T } \\
\text { CCP } \\
\text { R-O }\end{array}$ & $\begin{array}{c}\text { FAD: } \\
\text { API }\end{array}$ & $\begin{array}{c}\text { FAD: } \\
\sigma-\varepsilon\end{array}$ & $\begin{array}{c}\text { FAD: } \\
\text { R-O }\end{array}$ \\
\hline $6 \mathrm{ksi}$ & 82.4 & 73.2 & 74.9 & 68.8 & 131.7 & 118.2 & 124.1 & 109.2 \\
\hline $12 \mathrm{ksi}$ & 43.9 & 36.6 & 39.2 & 32.4 & 71.3 & 56.0 & 61.8 & 48.6 \\
\hline $18 \mathrm{ksi}$ & 25.0 & 22.6 & 24.9 & 18.8 & 44.1 & 33.6 & 39.9 & 29.0 \\
\hline $24 \mathrm{ksi}$ & 11.8 & 14.0 & 16.9 & 11.0 & 25.7 & 21.4 & 22.5 & 18.6 \\
\hline $30 \mathrm{ksi}$ & 4.6 & 8.0 & 10 & 6.2 & 12.9 & 13.4 & 11.0 & 12.0 \\
\hline $36 \mathrm{ksi}$ & 1.8 & 3.8 & 2.4 & 3.2 & 5.7 & 7.4 & 6.2 & 3.6 \\
\hline
\end{tabular}

The notations used in the above tables are

J-T CCP R-O: a J-T fracture methodology using the center-cracked panel (CCP) Jintegral solution with a curvature correction and Ramberg-Osgood stress-strain curve idealization.

J-T FEA R-O: a J-T fracture methodology with the J-integral obtained by finite element analysis and using the Ramberg-Osgood stress-strain curve idealization.

$J-T$ FEA $\sigma-\varepsilon$ : a J-T fracture methodology with J-integral obtained by finite element analysis and using the actual stress-strain curve of the material. 
FAD API: the general FAD approach recommended by the American Petroleum Institute.

FAD $\sigma-\varepsilon$ : a material-specific FAD using the actual stress-strain curve of the material.

FAD R-O: a material-specific FAD using the Ramberg-Osgood stress-strain curve idealization.

The fracture criterion for the A285 steel is given by

$$
\mathrm{J}_{\text {applied }} \geq \mathrm{J}_{\text {material cut-off }} \text { ( or } \mathrm{J}_{\text {crit }} \text { ), }
$$

That is, when the applied total J-integral value ( $\left.\mathrm{J}_{\text {applied }}\right)$, a function of flaw size and stress state, exceeds a cut-off value in the material $\mathrm{J}$ ( $\mathrm{J}_{\text {material cut-off }}$ or $\mathrm{J}_{\text {crit }}$ ) determined in mechanical property testing, the flaw will become unstable. SThe $J_{\text {applied }}$ may be calculated exactly using the finite element analysis to provide a "best estimate" of J. This was done for the Type I waste tank (results in column J-T FEA $\sigma-\varepsilon$ in Table 1) to validate the methodologies that use an estimation scheme for $\mathrm{J}_{\text {applied. }}$ The FAD approach does not provide $\mathrm{J}_{\text {applied }}$ directly. However, the FAD curve provides the assessment locus to evaluate flaw stability and the FAD results can be directly compared to those from the Jintegral analysis.

The results of the calculated instability lengths show that the J-T methodology that uses an estimated $\mathrm{J}_{\text {applied }}$ (see J-T CCP R-O column in Table 1), and the material-specific FAD (see FAD $\sigma-\varepsilon$ column), most closely approximate $\mathrm{J}_{\text {applied }}$ calculated using finite element analysis (see J-T FEA $\sigma-\varepsilon$ column) for the range of stress conditions that bound those expected at the highest fill levels in the waste tanks $(<18 \mathrm{ksi})$. The results from the other FAD methods show instability lengths less than the J-T results over this range. Additional conclusions are listed in Section 8 of this report.

\footnotetext{
$\S$ Material testing and analysis show that at the conditions of the Type I and Type II tanks, stable ductile tearing precedes instability. Based on this fundamental materials behavior and that the mechanical test specimen design provides for valid $\mathrm{J}$ up to several $\mathrm{mm}$, the material $\mathrm{J}$-value at $3 \mathrm{~mm}$ of stable crack extension, $\mathrm{J}_{3 \mathrm{~mm}}$, has been selected as the material cut-off for A285 steel.
} 


\section{$2.0 \quad$ INTRODUCTION}

The analysis to determine flaw stability requires inputs of material properties and stress conditions to a fracture mechanics methodology. Activities in the Life Management Program for the Type I and II high level waste tanks cover the development of these inputs at tank-specific conditions. The present report provides a comprehensive review of fracture mechanics methods that are appropriate for the Type I and II tanks. A comparison of these methods at a range of stress conditions at a specific set of mechanical property conditions for A285 steel is made in order to identify those fracture methods that provide for the maximum flaw stability lengths.

The DOE Order 435.1 [1,2,3] specifies the guidelines for waste tank structural integrity programs contained in the report BNL-52527 [4] that was prepared by a DOE-ER commissioned expert panel, the Tank Structural Integrity Panel (TSIP). The SRS tanks are operated at temperatures above $70^{\circ} \mathrm{F}$ to avoid the potential for brittle fracture [5]. The TSIP recognized that the carbon steel tanks are ductile under these conditions and stated that the material would experience stable crack extension prior to failure and that failure would occur by tearing of the metal [4]. Stable crack extension requires an increasing load (stress) to increase the length of the crack. Critical crack dimensions may be determined by elastic-plastic fracture mechanics (EPFM) or the limit load approach [4]. Two elastic-plastic fracture mechanics methods were recommended by the TSIP for determining the critical crack size [4]:

- J-Integral Analysis

- Failure Assessment Diagram.

Fill limits for the SRS high-level waste tanks were previously developed based on a limit load methodology [6] to avoid crack instability leading to a large rupture. This report reviews the J-Integral and $\mathrm{FAD}$ fracture methodologies to evaluate flaw stability for a postulated through-wall axial crack in the Type I and II waste tanks.

This report provides the following:

- Description of the two general methodologies and the details of the various types of estimation and assessment methods within these two categories

- Calculations of flaw instability lengths in Type I and II tanks over the range of stress conditions

- Comparison of the results

- Validation of the results through finite element analysis to exactly calculate the Jintegral with the input of a stress-strain curve for a specific A285 steel.

A comparison of the J-integral-tearing modulus $(\mathrm{J}-\mathrm{T})$ and several failure assessment diagrams (FAD) recommended in the API-579 (American Petroleum Institute Fitnessfor-Service, first edition, January 2000) [7] Level 3 analysis has been performed. The API assessments include (1) Method A: General FAD based on the CEGB (Central Electric Generating Board, U.K.) R6 (Assessment of the Integrity of Structures 
Containing Defects [8]) Option 1; (2) Method B: Material-specific FAD which is the CEGB R-6 Option 2 using the actual stress-strain curve of the material [9]; (3) Method C: J-based FAD utilizing the finite element fracture mechanics calculations (CEGB R-6 Option 3); and (4) Method D: Ductile tearing FAD with assessment points evaluated with an actual fracture resistance (J-R) curve [10]. The geometry of a through-wall axial flaw in the waste tank is used as a benchmark to illustrate the various fracture methodologies. Only a hoop stress loading is considered and no factors of safety are applied.

The finite element method was performed to validate the $\mathrm{J}$ estimation method that is based on a center-cracked panel (CCP) solution [11] with a curvature correction for the tank geometry [12-14]. The finite element result was also used to construct a failure assessment diagram following API 579 Level 3 Method C [7]. The instability crack lengths derived from these approaches were compared. The comparison is made within a range of fracture energies (e.g., $\mathrm{J}_{\mathrm{IC}}$ and $\mathrm{J}_{3 \mathrm{~mm}}$ ) and applied stresses to ensure equivalency and to justify use of the FAD approach for flaw stability analysis. The finite element method to calculate $\mathrm{J}$ is the "best-estimate" method to determine the instability flaw size.

Section 3 of the report describes the specific material property inputs. The stress-strain data are shown to be approximated by a Ramberg-Osgood equation and the material fracture resistance curve (J-R) is expressed as a power law. The J-integral methodology is reported in Section 4. The solution scheme of the CCP J-integral solution and the curvature correction are also described. Section 5 discusses the FAD formulations and the approaches recommended by API 579 [7]. Section 6 compares the calculated instability crack lengths using the J-T estimation and the FAD methodologies. The finite element analysis is described in Section 7. The results were used to validate the CCP estimation method and to construct a finite-element-based FAD. Section 8 discusses advanced fracture mechanics methodologies under development. Section 9 summarizes the conclusions.

\subsection{MATERIAL PROPERTIES}

The E400 heat of A285 steel was chosen for the material input to the analyses. The tensile tests in Reference 9 followed the American Society for Testing and Materials (ASTM) E8-99 "Standard Test Methods for Tension Testing of Metallic Materials." The fracture testing [10] was based on ASTM E1820-99 "Standard Test Method for Measurement of Fracture Toughness." The true stress-true strain curve along with the Ramberg-Osgood idealization is shown in Figure 1. The tensile test specimen was E40031 [9] which was tested at $80^{\circ} \mathrm{F}$ with tensile axis parallel to the plate rolling direction. The J-R curve in Figure 2 was obtained with a compact tension specimen E400-L1 [10] tested at $70^{\circ} \mathrm{F}$. The notch was perpendicular to the rolling direction of the plate. The power law fit of the J-R curve can also be found in Figure 2. The Young's modulus of the material is $30,000 \mathrm{ksi}$, the $0.2 \%$ yield stress is $36.1 \mathrm{ksi}$, and the Poisson's ratio is 0.3 . The J-R curve in Figure 2 provides $\mathrm{J}_{\mathrm{IC}}=1093 \mathrm{in}-\mathrm{lb} / \mathrm{in}^{2}$ and $\mathrm{J}_{3 \mathrm{~mm}}=3567 \mathrm{in}-\mathrm{lb} / \mathrm{in}^{2}$, where $\mathrm{J}_{\mathrm{IC}}$ is the $J$ value at crack initiation and $J_{3 \mathrm{~mm}}$ is the $J$ value evaluated at $3 \mathrm{~mm}$ crack extension in the fracture testing. 


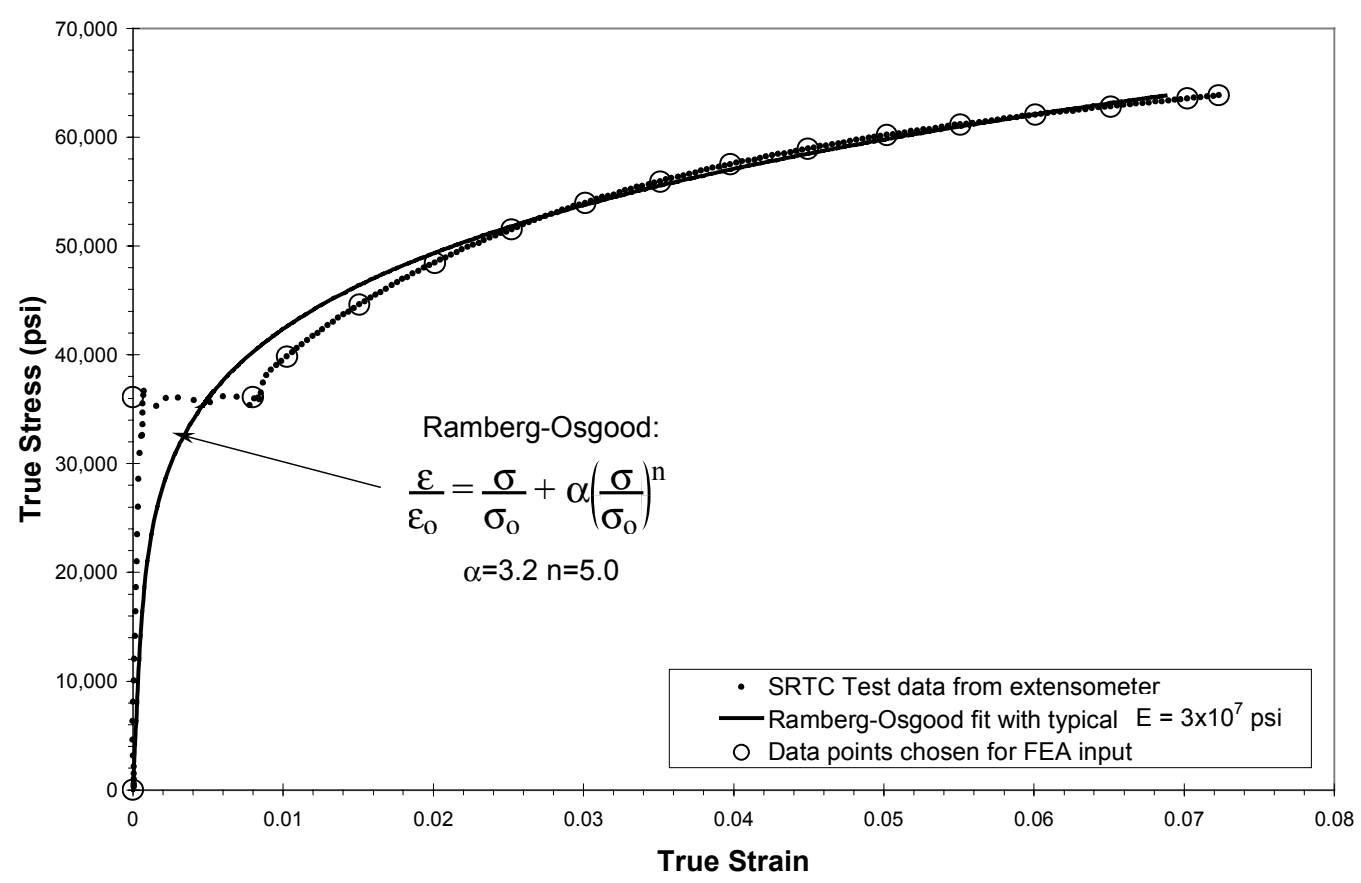

Figure 1. True Stress-True Strain Curve of A285 E400 Steel

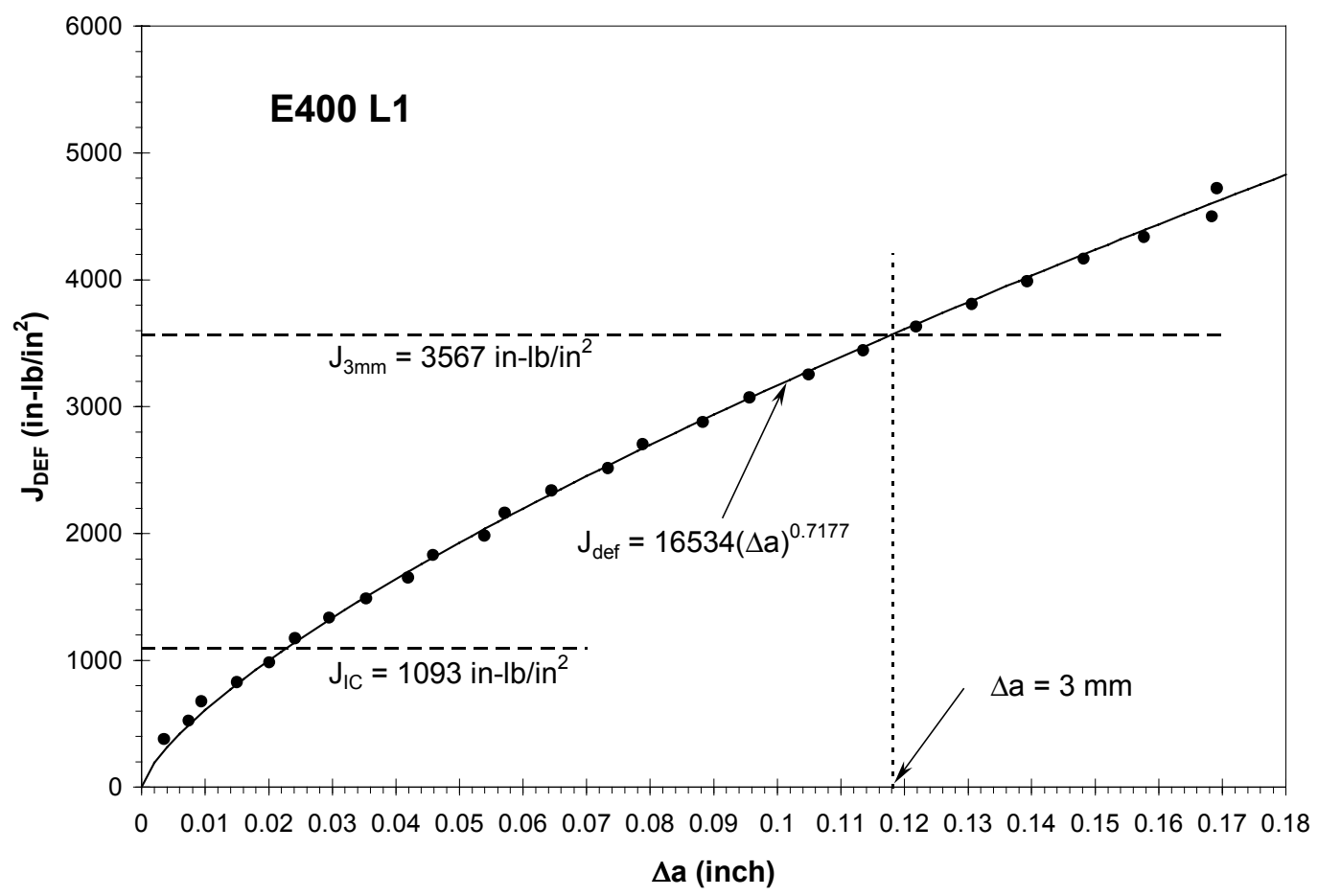

Figure 2. J-R Curve of A285 E400 Steel 


\subsection{J-INTEGRAL METHODOLOGY}

An overview of the J-integral methodology is described below. An estimation method for evaluating J-integral in a curved structure is discussed. The residual stress (or other secondary stresses) can be included in a general estimation procedure.

\subsection{Flaw Stability}

The fracture properties and J-R curves are normally determined by the testing methods described in the ASTM standards. The J-R curve represents the material resistance of ductile crack growth and the test data are typically fit with a power law expression:

$\mathrm{J}=\mathrm{C}(\Delta \mathrm{a})^{\mathrm{m}}$

where $\mathrm{C}$ and $\mathrm{m}$ are curve fitting parameters (Fig. 2).

The tearing stability of the material is characterized by the tearing modulus (T) which is proportional to the slope of the $\mathrm{J}-\mathrm{R}$ curve $(\mathrm{dJ} / \mathrm{da})$ and is defined as

$$
\mathrm{T}=\frac{\mathrm{E}}{\sigma_{\mathrm{o}}^{2}} \frac{\mathrm{dJ}}{\mathrm{da}}
$$

where $\mathrm{J}$ is the value of J-integral, $\sigma_{\mathrm{o}}$ is the $0.2 \%$ yield stress, and $\mathrm{E}$ is the Young's modulus. Instability flaw lengths are evaluated based on the loading conditions of the structural component and are determined by an elastic-plastic J-integral or J-T analysis. The crack growth $\left(\mathrm{J} \geq \mathrm{J}_{\mathrm{IC}}\right)$ is stable if $\mathrm{T}<\mathrm{T}_{\mathrm{R}}$, where $T_{R}$ is the tearing modulus of the material. The intersection point of the applied J-T curve and the material J-T curve will define the stable crack growth limit $[15,16]$. This procedure is schematically shown in Figure 3. 


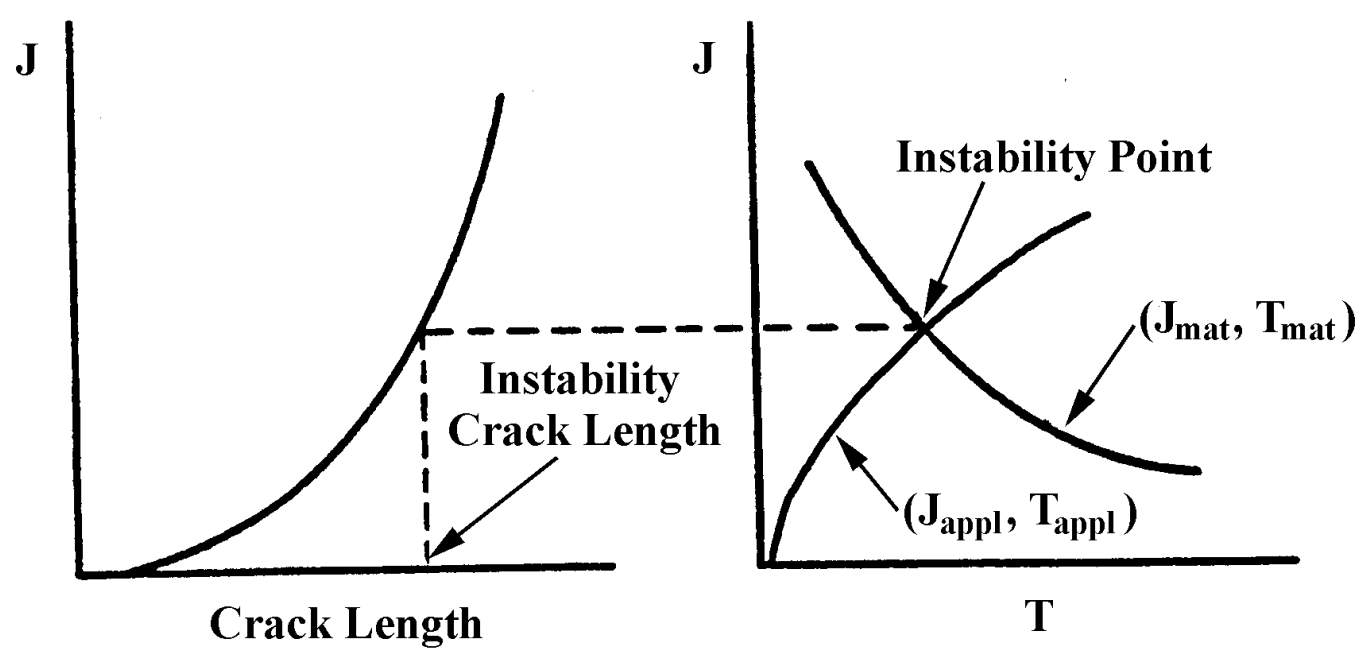

Figure 3. Determination of Instability Crack Length with J-T Methodology

\subsection{Cut-off for J-controlled Crack Growth}

The designs of specimens for J-R fracture property testing ensure a certain amount of stable crack growth can be obtained. Typically, the specimens do not generate data to the point where unstable crack growth begins. Therefore, extrapolation of the data could be made to determine the flaw instability (Fig. 4). However, a conservative approach is to "cut-off" the material toughness data and to apply that cut-off value in the flaw stability analyses [17].

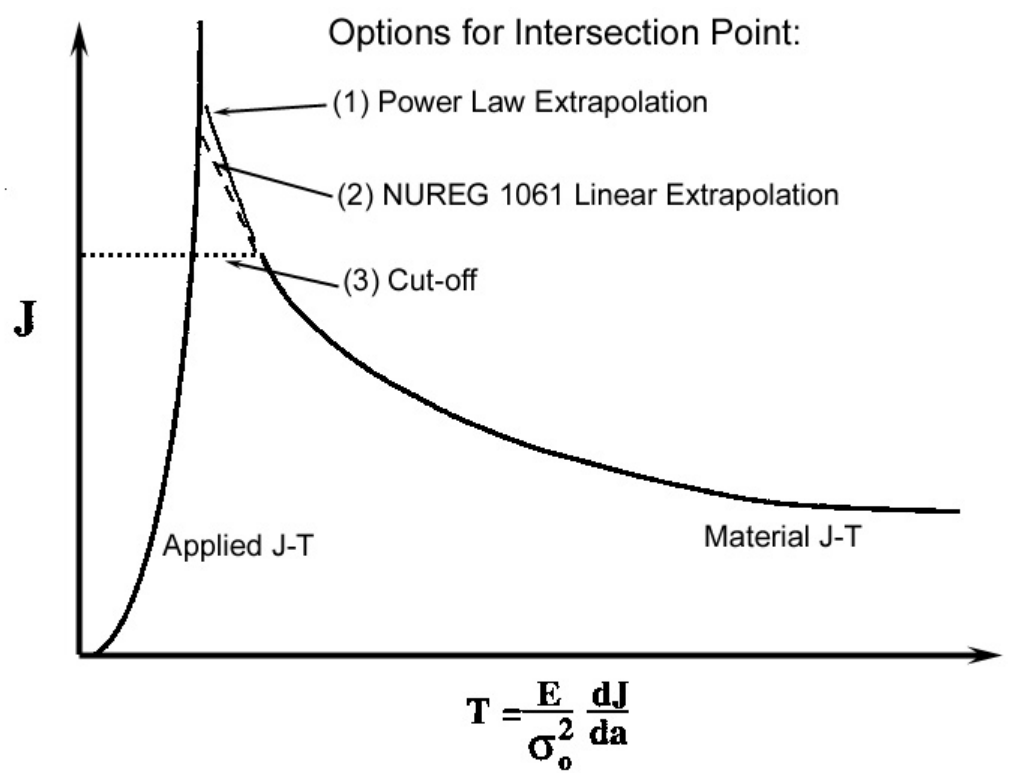

Figure 4. Extrapolation of Material J-T Curve to Intersect Applied J-T Curve 
A typical J-T calculation for an axial crack in a tank is seen in Figure 5 which shows no intersection point can be achieved, unless the material J-T curve was extrapolated extensively. Under these circumstances, a cut-off $\mathrm{J}$ value at $3 \mathrm{~mm}$ crack extension [10] may be conservatively used (rather than extrapolating to a much higher $\mathrm{J}$ value) to determine the instability crack length. The design of the fracture testing specimen has allowed valid data up to approximately $3 \mathrm{~mm}$ extension in crack length [10].
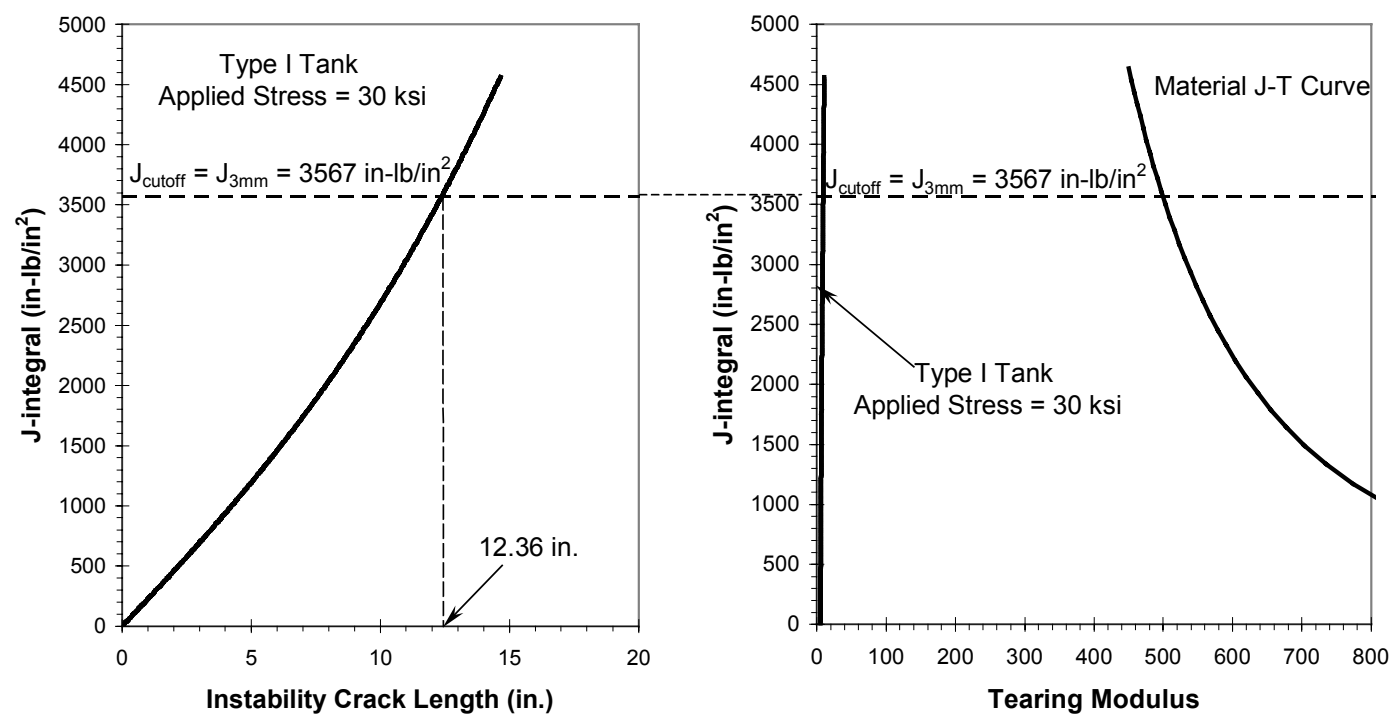

Figure 5. Typical J-T Curves for Determining Instability Crack Length

The $\mathrm{J}_{\mathrm{IC}}$ ( $\mathrm{J}$ at crack initiation) was also used for estimating the instability crack length. In this case no credit was taken for the stable crack growth expected in ductile materials.

\subsection{J-Integral Estimation Method}

Prior to the $\mathrm{J}$ calculation and a curvature correction, the correspondence between the geometry of a center-cracked panel (CCP) and a cylindrical body containing an axial crack is shown in Figures 6 (a circumferential crack can be treated similarly [12$14,18,19])$. This Section describes the details for estimating J-integral in a finite sized CCP. 

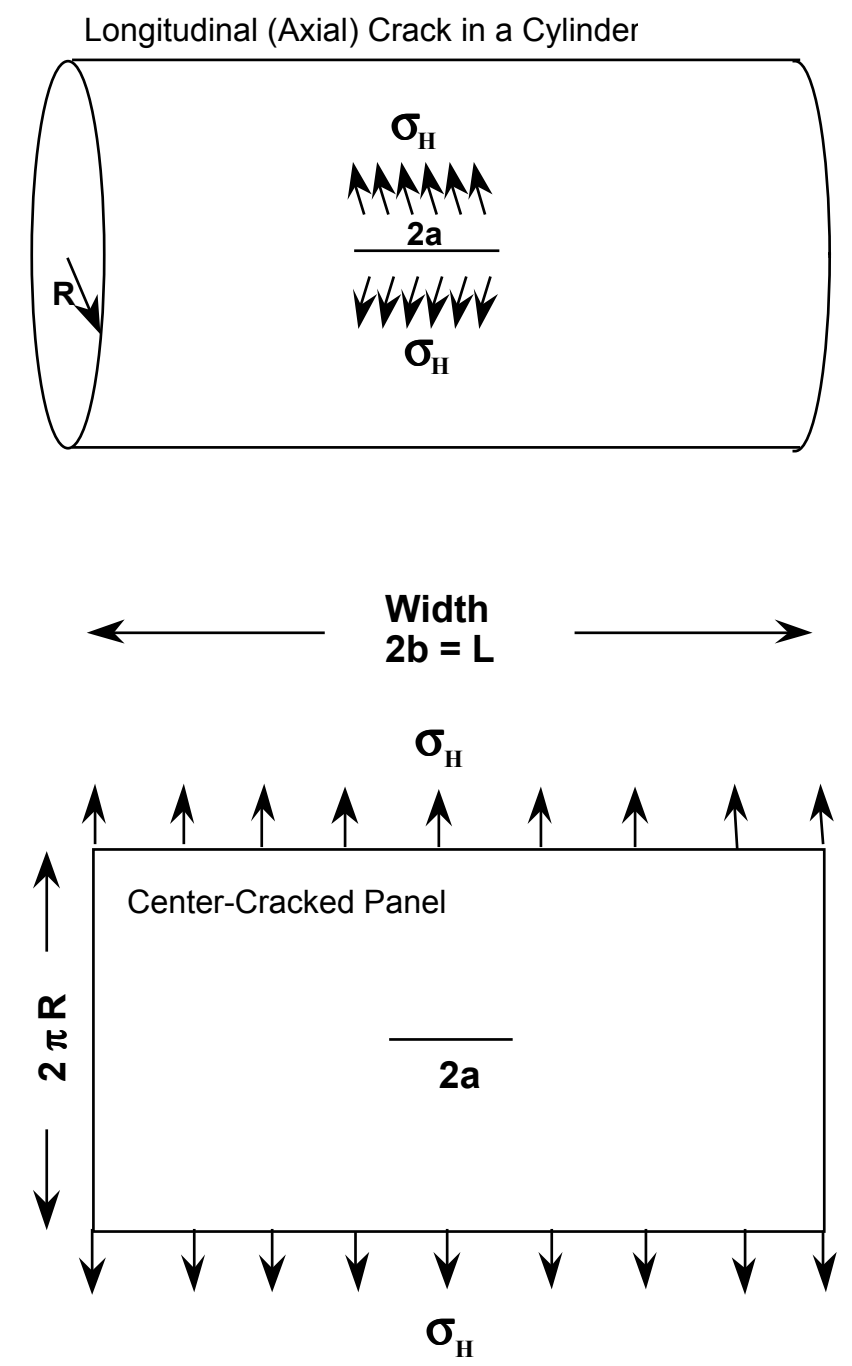

Figure 6. Correspondence Between an Axial Crack and a Center-Cracked Panel

The material constitutive equation utilizes the Ramberg-Osgood power law idealization:

$$
\frac{\varepsilon}{\varepsilon_{0}}=\frac{\sigma}{\sigma_{0}}+\alpha\left(\frac{\sigma}{\sigma_{0}}\right)^{\mathrm{n}}
$$

where $\sigma_{\mathrm{o}}$ is a reference stress or the $0.2 \%$ yield stress, $\varepsilon_{\mathrm{o}}$ is $\sigma_{\mathrm{o}} / \mathrm{E}, \mathrm{E}$ is the Young's modulus of the material, $\alpha$ is the yield offset, and $\mathrm{n}$ is the hardening exponent. Both $\alpha$ and $\mathrm{n}$ are obtained from curve fitting of the tensile test data. Figure 1 shows the true stress-true strain curve and the Ramberg-Osgood fit for the present analysis.

The CCP solution was originally developed for a tensile crack in a finite plate. The general expression for $\mathrm{J}$ has an elastic portion $\left(\mathrm{J}^{\mathrm{e}}\right)$ and a plastic portion $\left(\mathrm{J}^{\mathrm{p}}\right)$ :

$$
J=J^{e}\left(a_{e}, P\right)+J^{p}(a, n, P)=\hat{J}\left(a_{e}\right)\left[P / P_{o}\right]^{2}+\hat{J}(a, n)\left[P / P_{o}\right]^{n+1}
$$


where $2 \mathrm{a}$ is the crack length, $2 \mathrm{a}_{\mathrm{e}}$ is the adjusted crack length, $\mathrm{P}$ is the applied load, $\mathrm{P}_{\mathrm{o}}$ is a reference load or the limit load for the cracked configuration, and $\hat{\mathrm{J}}$ is a function of crack length and the material hardening exponent (n).

For a Ramberg-Osgood material (Eq. 2) obeying deformation theory of plasticity, Shih and Hutchinson [11] showed that

$\frac{\mathrm{J}}{\sigma_{\mathrm{o}} \varepsilon_{\mathrm{o}} \mathrm{a}(1-\mathrm{a} / \mathrm{b})}=\psi\left(\frac{\mathrm{P}}{\mathrm{P}_{\mathrm{o}}}\right)^{2} \mathrm{~g}_{1}\left(\frac{\mathrm{a}_{\mathrm{eff}}}{\mathrm{b}}, \mathrm{n}=1\right)+\alpha\left(\frac{\mathrm{P}}{\mathrm{P}_{\mathrm{o}}}\right)^{\mathrm{n}+1} \mathrm{~g}_{1}\left(\frac{\mathrm{a}_{\mathrm{eff}}}{\mathrm{b}}, \mathrm{n}\right)$.

Therefore, its elastic portion is

$\mathrm{J}_{\mathrm{el}}^{\mathrm{ccp}}=\psi \sigma_{\mathrm{o}} \varepsilon_{\mathrm{o}} \mathrm{a}(1-\mathrm{a} / \mathrm{b})\left(\frac{\mathrm{P}}{\mathrm{P}_{\mathrm{o}}}\right)^{2} \mathrm{~g}_{1}\left(\frac{\mathrm{a}_{\mathrm{eff}}}{\mathrm{b}}, \mathrm{n}=1\right)$

and the plastic portion is

$\mathrm{J}_{\mathrm{pl}}^{\mathrm{ccp}}=\alpha \sigma_{\mathrm{o}} \varepsilon_{\mathrm{o}} \mathrm{a}(1-\mathrm{a} / \mathrm{b})\left(\frac{\mathrm{P}}{\mathrm{P}_{\mathrm{o}}}\right)^{\mathrm{n}+1} \mathrm{~g}_{1}\left(\frac{\mathrm{a}_{\mathrm{eff}}}{\mathrm{b}}, \mathrm{n}\right)$,

where $a$ is the half crack length, $b$ is the half specimen width (Fig.6),

$\varepsilon_{\mathrm{o}}=\sigma_{\mathrm{o}} / \mathrm{E}$

$\mathrm{a}_{\text {eff }}=\mathrm{a}+\varphi \mathrm{r}_{\mathrm{y}}, \mathrm{P} \leq \mathrm{P}_{\mathrm{o}} \mathrm{O}$

$\mathrm{a}_{\mathrm{eff}}=\left(\mathrm{a}_{\mathrm{eff}}\right)_{\mathrm{P}=\mathrm{P}_{\mathrm{o}}}, \mathrm{P}>\mathrm{P}_{\mathrm{o}}$,

$\varphi=\frac{1}{1+\left(\mathrm{P} / \mathrm{P}_{\mathrm{o}}\right)^{2}}$,

$\mathrm{P}_{\mathrm{o}}=2(\mathrm{~b}-\mathrm{a}) \sigma_{\mathrm{o}}$ is the lower bound limit load,

$\mathrm{P}=2 \mathrm{~b} \sigma^{\infty}$ is the applied load corresponding to a remote stress $\sigma^{\infty}$,

$\mathrm{r}_{\mathrm{y}}=\frac{1}{2 \pi}\left(\frac{\mathrm{n}-1}{\mathrm{n}+1}\right)\left(\frac{\mathrm{K}_{\mathrm{I}}}{\sigma_{\mathrm{o}}}\right)^{2}=\frac{\mathrm{a}}{2 \pi}\left(\frac{\mathrm{n}-1}{\mathrm{n}+1}\right)\left(1-\frac{\mathrm{a}}{\mathrm{b}}\right)\left(\frac{\mathrm{P}}{\mathrm{P}_{\mathrm{o}}}\right)^{2} \mathrm{~g}_{1}\left(\frac{\mathrm{a}}{\mathrm{b}}, 1\right)$ for plane stress, and

$\psi=\frac{\mathrm{a}_{\mathrm{eff}}}{\mathrm{a}}\left(\frac{\mathrm{b}-\mathrm{a}}{\mathrm{b}-\mathrm{a}_{\mathrm{eff}}}\right)$.

$\dagger$ This equation is a modification of the one that originally appeared in Reference 11 by introducing a parameter $\varphi$ which was proposed in "Fully Plastic Crack Solutions, Estimation Scheme, and Stability Analyses for the Compact Specimen," by V. Kumar and C. F. Shih, in Fracture Mechanics: Twelfth Conference, ASTM STP 700, American Society for Testing and Materials, 1980, pp. 406-438. 
and

$\mathrm{g}_{1}\left(\frac{\mathrm{a}}{\mathrm{b}}, 1\right)=\pi\left[1-0.5 \frac{\mathrm{a}}{\mathrm{b}}-0.37\left(\frac{\mathrm{a}}{\mathrm{b}}\right)^{2}-0.044\left(\frac{\mathrm{a}}{\mathrm{b}}\right)^{3}\right]^{2}$

For the A285 Grade B carbon steel, the tensile properties were obtained from an E-400 heat specimen [9]. The Ramberg-Osgood exponent $\mathrm{n}$ is 5 and the yield offset $\alpha$ is 3.2 (Fig. 1). Therefore, the values for $\mathrm{g}_{1}(\mathrm{a} / \mathrm{b}, \mathrm{n}=5)$ can be calculated according to the procedure described in Reference 11:

$\begin{array}{cc}\mathrm{a} / \mathrm{b} & \mathrm{g}_{1}(\mathrm{a} / \mathrm{b}, \mathrm{n}=5) \\ 0 & 7.515 \\ 1 / 8 & 4.518 \\ 1 / 4 & 3.195 \\ 1 / 2 & 1.811 \\ 3 / 4 & 1.208 \\ 1 & 0.835\end{array}$

\subsection{Curvature Corrections}

A curvature correction is applied to estimate the J-integral values for the through-wall flaws in the sidewall of a tank. In the linear elastic fracture mechanics, the stress intensity factor $(K)$ of a crack is usually expressed in a general form $K=Y \sigma \sqrt{\pi \mathrm{a}}$, where $\sigma$ is the applied stress and $\mathrm{Y}$ is a function of crack size and specimen dimensions. In the linear elastic regime, $\mathrm{J} \propto \mathrm{K}^{2}$. The curvature correction factor, for estimating J-integral of a crack in a curved structure based on a corresponding infinite flat plate solution with the same crack length, is therefore $\mathrm{Y}^{2}$.

The curvature correction factors for a tank or a pipe can be obtained with handbook solutions, such as Reference 20 by Erdogen, and Reference 21 by Rooke and Cartwright. The solutions provided by Tada et al. [22] are simpler to use and the solutions are more representative in some cases. For an axial (longitudinal) crack, the solution in Reference 22 is used. The stress intensity factor of an axial crack with length 2 a subjected to a hoop stress $\sigma_{H}$ in a cylinder with mean radius $R$ and thickness $t$ is

$\mathrm{K}_{\mathrm{I}}=\sigma_{\mathrm{H}} \sqrt{\pi \mathrm{a}} \mathrm{Y}(\lambda)$

where $\lambda=\frac{\mathrm{a}}{\sqrt{\mathrm{Rt}}}$,

$Y(\lambda)=\sqrt{1+1.25 \lambda^{2}}$ for $0<\lambda \leq 1$

and 
$\mathrm{Y}(\lambda)=0.6+0.9 \lambda$, for $1 \leq \lambda \leq 5$

In this case the curvature correction factor for the J-integral of an axial or a longitudinal crack is $\mathrm{Y}^{2}$.

\subsection{General Procedure for Combining J-integral Contributions}

The J-integral is typically calculated with only the primary loads acting on the structural component. $\mathrm{f}$ However, a procedure commonly used to readily combine the secondary stress and/or residual stress contributions to the J-integral was developed previously [1215]. This procedure is summarized in the following:

(1) For a given applied stress, calculate the CCP solution of Shih and Hutchinson [11] for various crack lengths. The $\mathrm{J}$-integral $\left(\mathrm{J}^{\mathrm{ccp}}\right)$ is composed of an elastic portion $\left(\mathrm{J}_{\mathrm{el}}^{\mathrm{ccp}}\right)$ and a plastic portion $\left(\mathrm{J}_{\mathrm{pl}}^{\mathrm{ccp}}\right)$, that is, $\mathrm{J}^{\mathrm{ccp}}=\mathrm{J}_{\mathrm{el}}^{\mathrm{ccp}}+\mathrm{J}_{\mathrm{pl}}^{\mathrm{ccp}}$.

(2) The plastic zone size correction (or small scale yielding correction) is applied to $J_{\mathrm{el}}^{\mathrm{ccp}}$.

(3) The CCP solution is corrected for the curvature of the shell or cylindrical structure. The approximated $\mathrm{J}$-integral values for cracks in a tank ( $\mathrm{J}_{\mathrm{el}}^{\mathrm{cur}}$ and $\mathrm{J}_{\mathrm{pl}}^{\mathrm{cur}}$ ) are $\mathrm{J}_{\mathrm{el}}^{\mathrm{cur}}=\mathrm{Y}^{2} \mathrm{~J}_{\mathrm{el}}^{\mathrm{ccp}}$ and $\mathrm{J}_{\mathrm{pl}}^{\mathrm{cur}}=\mathrm{Y}^{2} \mathrm{~J}_{\mathrm{pl}}^{\mathrm{ccp}}$, respectively.

(4) The contributions of the stress intensity factor (K) from the other sources, such as the thermal stress or the residual stress, can be combined in the sense of linear elastic fracture mechanics. The elastic portion of J-integral $\left(\mathrm{J}_{\mathrm{el}}^{\mathrm{cur}}\right)$ in $(3)$ above is first converted to $\mathrm{K}_{\mathrm{I}}^{\text {appl }}$ : the Mode I stress intensity factor due to the applied load is $\mathrm{K}_{\mathrm{I}}^{\mathrm{appl}}=\sqrt{\mathrm{E} \mathrm{J}} \mathrm{el}$ under plane stress condition.

(5) Note that $\mathrm{K}_{\mathrm{I}}^{\text {res }}$ (stress intensity factor due to the residual stress) is saturated to a maximum value when the crack is extended in length only a fraction of the plate thickness $[23,24]$. Therefore, the residual stress of this type is not subject to curvature correction. A series of numerical solutions for the stress intensity factors were obtained by simulating the welding process and taking into consideration the effect of residual stress redistribution as a result of crack growth [24-26].

(6) The total elastic portion of $\mathrm{J}$ is calculated as $\mathrm{J}^{\mathrm{e}}=\frac{1}{\mathrm{E}}\left(\mathrm{K}_{\mathrm{I}}^{\mathrm{appl}}+\mathrm{K}_{\max }^{\mathrm{res}}\right)^{2}$.

(7) The plastic portion of $\mathrm{J}$ remains unchanged, that is, $\mathrm{J}^{\mathrm{p}}=\mathrm{J}_{\mathrm{pl}}^{\mathrm{cur}}$.

(8) Finally, the total $\mathrm{J}$-integral at the crack tip is $\mathrm{J}=\mathrm{J}^{\mathrm{e}}+\mathrm{J}^{\mathrm{p}}$.

It is noted that a similar combination scheme involving the conversion between the $\mathrm{J}$ integral and the stress intensity factor (K) was adopted in API 579 (Section 9.4.3 of [7]). This conversion, such as those used in (4) and (6) above, is strictly valid when the

$\$$ To calculate the J-integral accurately, a rigorous finite element analysis would be performed to simultaneously combine all the stresses including the residual stress. This is not done in practice due to the intensive modeling time required. 
material is linear elastic. This has also been recognized by API 579 Appendix F.4.2.1 [7]: "For most materials and structures covered by this document, it is possible to measure toughness only in terms of J and CTOD; valid $\mathrm{K}_{\mathrm{IC}}$ data can only be obtained for brittle materials or thick sections." The stress intensity factor at crack initiation, $\mathrm{K}_{\mathrm{IC}}$, is commonly referred to the fracture toughness of the material. Under plane strain small scale yielding conditions, the equivalent fracture parameter converted from the J-R data is denoted by $\mathrm{K}_{\mathrm{JC}}$.

\subsection{Results of J-T Approach}

The calculated instability crack length can be plotted as a function of the applied stress. The results of both Type I and II tanks are presented in Figure 7. Two fracture criteria were considered $\left(\mathrm{J}_{\text {crit }}=\mathrm{J}_{\mathrm{IC}}\right.$ for crack initiation and $\mathrm{J}_{\text {crit }}=\mathrm{J}_{3 \mathrm{~mm}}$ for taking advantage of material capability of ductile tearing). It is seen in Figure 7 that the difference between the instability crack lengths in the Type I and II tanks diminishes as the load increases.

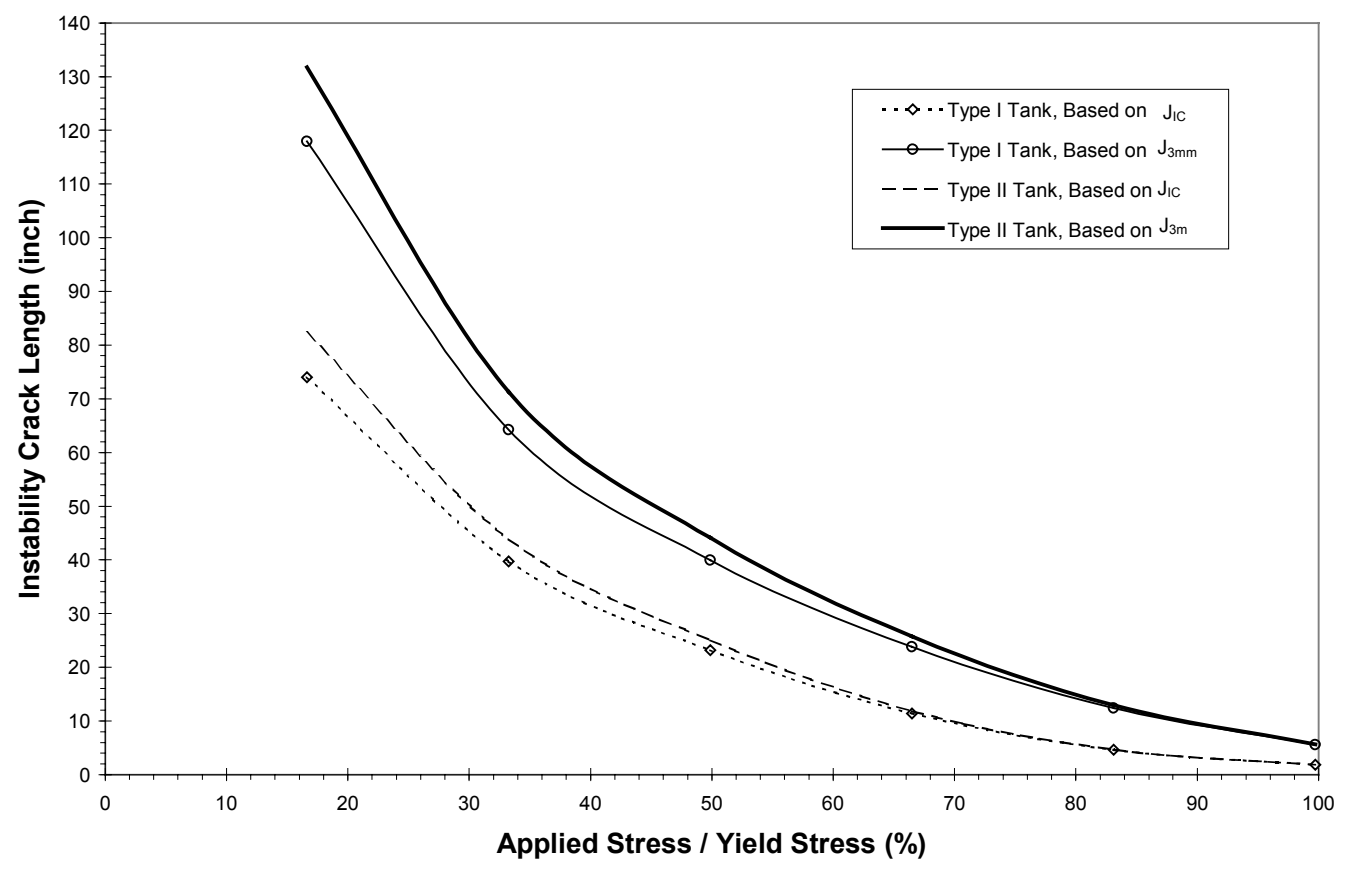

Figure 7. Instability Crack Lengths Determined with J-T Methodology

\subsection{FAILURE ASSESSMENT DIAGRAMS (FAD)}

The failure assessment diagram (FAD) is a crack growth resistance curve plotted in $\mathrm{L}_{\mathrm{r}}$ (abscissa) and $\mathrm{K}_{\mathrm{r}}$ (ordinate) space [16]. When the assessment point is below this curve, the crack is stable. In the nondimensional $\mathrm{L}_{\mathrm{r}}-\mathrm{K}_{\mathrm{r}}$ coordinate system, the stress ratio $\mathrm{L}_{\mathrm{r}}$ is defined as the ratio of the applied load $(\mathrm{P})$ to a reference load $\left(\mathrm{P}_{\mathrm{o}}\right)$; and $\mathrm{K}_{\mathrm{r}}$ and $\mathrm{J}_{\mathrm{r}}$ are the ratios of elastic force to the resisting force: 
$\mathrm{L}_{\mathrm{r}}=\mathrm{P} / \mathrm{P}_{\mathrm{o}}$

$\mathrm{K}_{\mathrm{r}}=\mathrm{K}(\mathrm{a}, \mathrm{P}) / \mathrm{K}_{\mathrm{R}}(\Delta \mathrm{a})$

$\mathrm{J}_{\mathrm{r}}=\mathrm{J}^{\mathrm{e}}(\mathrm{a}, \mathrm{P}) / \mathrm{J}_{\mathrm{R}}(\Delta \mathrm{a})$

where $\mathrm{K}$ is the stress intensity factor at the tip of a crack, and $\mathrm{K}_{R}$ is related to $J_{R}$ as $\mathrm{K}_{\mathrm{R}}^{2}(\Delta \mathrm{a})=\mathrm{E}^{\prime} \mathrm{J}_{\mathrm{R}}(\Delta \mathrm{a})$. This relation is strictly valid for linear elastic deformation or under small scale yielding conditions. The elastic portion of J-integral, $\mathrm{J}^{\mathrm{e}}$, is the elastic crack driving force and can be written as $\mathrm{J}^{\mathrm{e}}=\mathrm{K}^{2} / \mathrm{E}^{\prime}$. In these expressions, $\mathrm{E}^{\prime}=\mathrm{E}$ for plane stress, $E^{\prime}=E /\left(1-v^{2}\right)$ for plane strain, and $v$ is the Poisson's ratio. Under these circumstances, $\mathrm{K}_{\mathrm{r}}$ and $\mathrm{J}_{\mathrm{r}}$ are related by

$\mathrm{K}_{\mathrm{r}}^{2}(\mathrm{a}, \mathrm{P}, \Delta \mathrm{a})=\mathrm{J}_{\mathrm{r}}(\mathrm{a}, \mathrm{P}, \Delta \mathrm{a})$

\subsection{Original FAD}

The original formulation for the FAD is based on the Dugdale solution [27] or the strip yield model. That is

$$
\mathrm{J}\left(\mathrm{a}, \sigma^{\infty}\right)=\frac{8}{\pi} \sigma_{\mathrm{o}} \varepsilon_{\mathrm{o}} \mathrm{a}\left\{\ln \left[\sec \left(\frac{\pi}{2} \frac{\sigma^{\infty}}{\sigma_{\mathrm{o}}}\right)\right]\right\}
$$

where $\sigma^{\infty}$ is the remote applied stress. When the stable crack growth occurs, it is required that $\mathrm{J}=\mathrm{J}_{R}$, which is on the J-R curve. Therefore, the FAD curve becomes

$$
\frac{\mathrm{L}_{\mathrm{r}}^{2}}{\frac{8}{\pi^{2}} \ln \left[\sec \left(\frac{\pi}{2} \mathrm{~L}_{\mathrm{r}}\right)\right]}=\mathrm{J}_{\mathrm{r}}=\mathrm{K}_{\mathrm{r}}^{2}
$$

In the strip yield model of FAD, the reference load is the yield stress of the material. For a given crack with length $2 \mathrm{a}$ and tensile load $\mathrm{P}$, the assessment point in the FAD can be calculated with Eqs. 5-8. If the point is below the curve defined by Eq. 10, the crack is stable. If the point is located above the FAD, unstable crack growth is predicted. The original formulation of FAD is fully consistent with the J-integral approach when the plastic zone is limited to a line segment ahead of the crack tip (strip yield or cohesive zone model) and the surrounding material remains linear elastic. 


\section{$5.2 \quad$ J-Based FAD}

A more general formulation of FAD can be constructed with the J-integral estimation scheme $[11,28]$. Under the J-controlled crack growth and small scale yielding conditions, the fracture criterion $J(a, P)=J_{R}(\Delta a)$ leads to [29]

$\frac{\mathrm{L}_{\mathrm{r}}^{2}}{\mathrm{H}_{\mathrm{e}} \mathrm{L}_{\mathrm{r}}^{2}+\mathrm{H}_{\mathrm{n}} \mathrm{L}_{\mathrm{r}}^{\mathrm{n}+1}}=\mathrm{J}_{\mathrm{r}}=\mathrm{K}_{\mathrm{r}}^{2}$

where $H_{e}=\hat{J}\left(a_{e}\right) / \hat{J}(a)$ and $H_{n}=\hat{J}(a, n) / \hat{J}(a)$. The function $\hat{J}$ has been defined in Eq. 3. In this case, the reference load used to define $L_{r}$ should be consistent with that used in the $\mathrm{J}$ estimation scheme, and it may depend on the crack length.

This example shows that, in general, the J-based FAD is a function of crack size. It is no longer a single curve as defined by Eq. (10). More specifically, the FAD based on the J estimation scheme depends on the crack length (2a), material hardening exponent (n), type of loading (Eq. 3), and the type of deformation (plane stress or plane strain). As the flaw propagates, a new FAD should be constructed, unless it is judged that the crack increment is small enough not to cause a significant change in the shape of the FAD. Therefore, a family of failure assessment diagrams must be constructed with respect to each crack length.

It appears that the FAD approach based on the elastic-plastic J-integral (e.g., Eq. 11) may become more complex and cumbersome when the material-specific curves are to be used [29]. Similar information on flaw stability can be obtained in straightforward approaches such as the J-integral-tearing modulus (J-T) methodology. However, the family of failure assessment curves may be shown to collapse to a single curve by selecting a particular reference load [7,30]. This will be demonstrated in Section 7.4.

\subsection{API Recommended FAD Approaches}

The FAD methodologies recommended in API 579 Level 3 Analysis were followed to construct the failure assessment curves. Figure 8 contains various failure assessment curves that include 1) original FAD based on strip yield model; 2) API general FAD (Method A); 3) API material-specific FAD (Method B); 4) API finite element FAD (Method C); and 5) two additional curves for idealized Ramberg-Osgood materials. The instability crack lengths are obtained by increasing the crack length under a specific hoop stress until the assessment locus intersects the FAD. The assessment points can be determined by the guidelines in API 579 Section 9, Appendices B, C, and D [7]. 


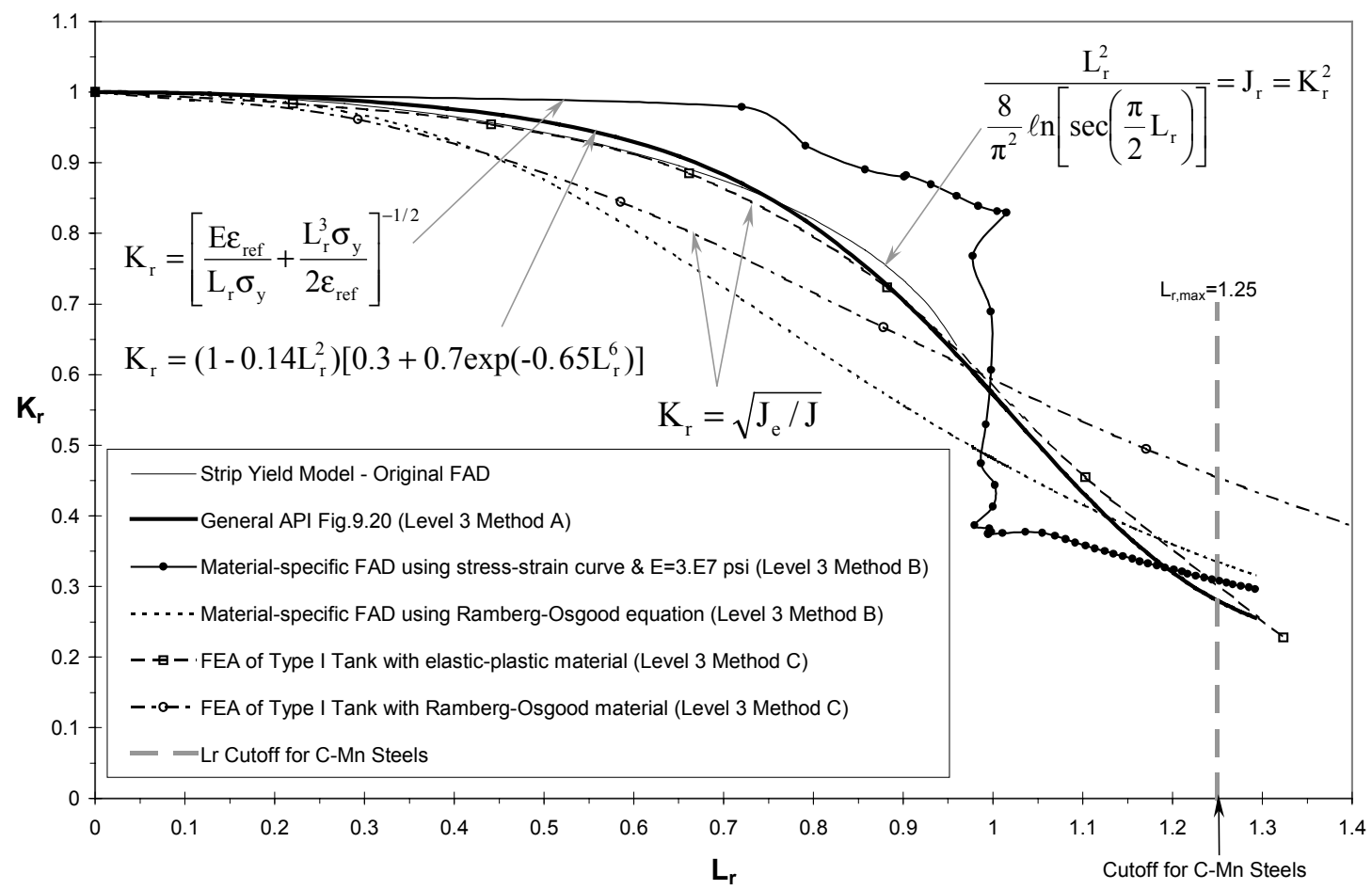

Figure 8. API 579 Recommended Failure Assessment Diagrams

\subsection{Determination of Instability Crack Length Based on FAD}

Figure 9 is used to illustrate the process of obtaining an instability crack length for a given load (or hoop stress in this report). Two load cases are used for demonstration: 6 ksi and $18 \mathrm{ksi}$. The crack length is increased incrementally until the assessment locus intersects the FAD. The calculation procedure for the $\left(\mathrm{L}_{\mathrm{r}}, \mathrm{K}_{\mathrm{r}}\right)$ coordinates of the assessment point can be found in API 579 [7]. The crack length corresponding to the intersection point is the instability crack length under that applied load (or stress). Figure 9 shows the instability crack lengths (66.4 and 20.2 inches, respectively) determined by the general FAD (API 579 Level 3 Method A Assessment) [7]. Similarly, if a materialspecific FAD is used (also see Figure 9), the instability crack length is then obtained by API 579 Level 3 Method B Assessment [7]. It is clear that at these two loading levels, the instability crack lengths determined with the material-specific FAD are longer than those obtained by the general FAD. 


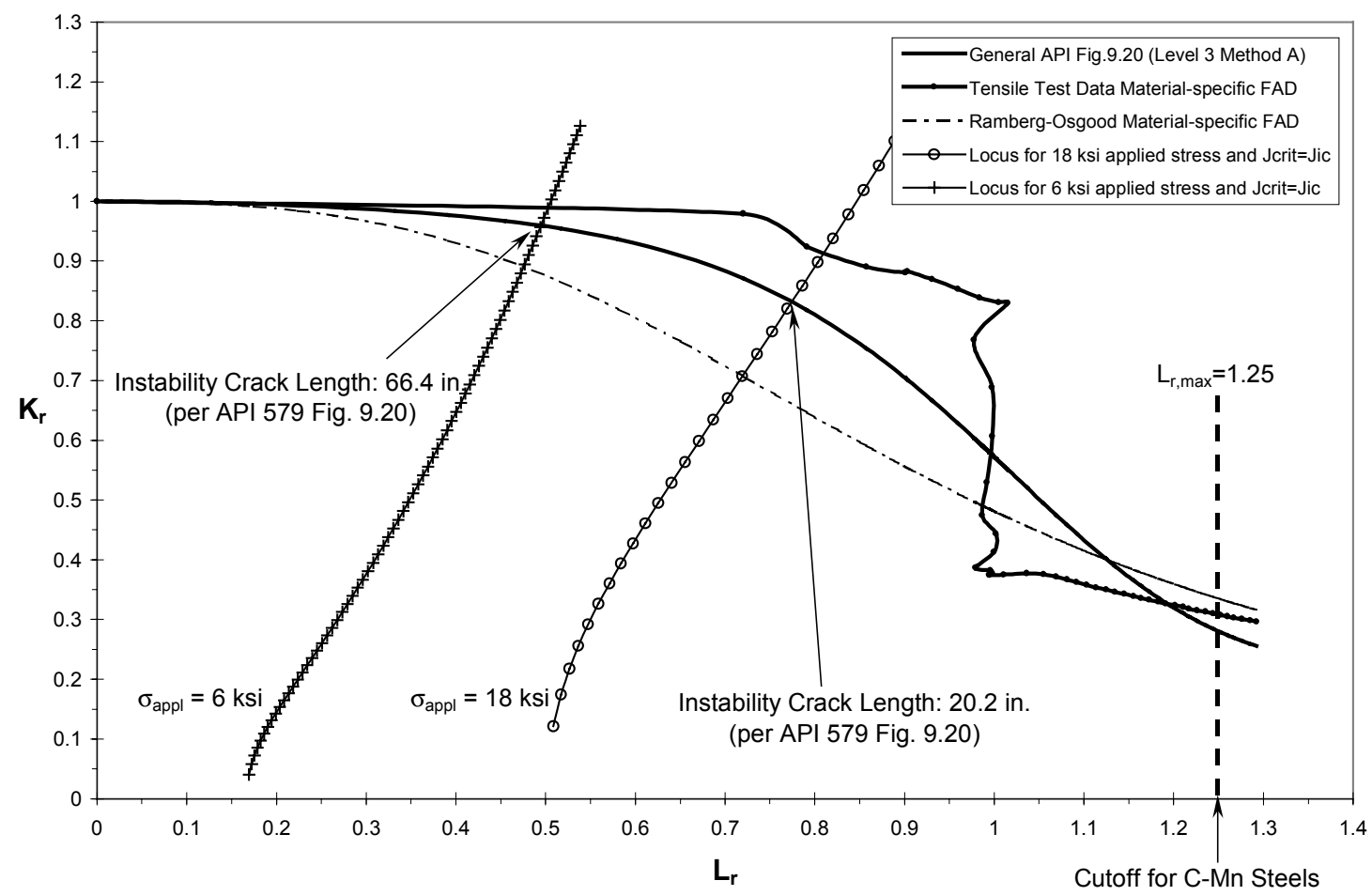

Figure 9. Determination of Instability Crack Length using FAD Approach

Another FAD approach for determining the instability crack length is suggested by API 579 Level 3 Method D Assessment [7]. It is appropriate for materials which exhibit ductile tearing and the experimental J-R curves are available. The assessment locus uses the $J$ values on the $J-R$ curve (depending on the amount of crack extension) that produces a fishhook shape as seen in the inset of Figure 10. However, if the J-R curve is cut off for practical reasons, as the $\mathrm{J}_{3 \mathrm{~mm}}$ in the present $\mathrm{J}-\mathrm{T}$ analysis, this type of FAD analysis is identical to the standard procedure with $\mathrm{K}_{\mathrm{r}}=\sqrt{\mathrm{J}_{\mathrm{e}} / \mathrm{J}_{\text {crit }}}$, in which $\mathrm{J}_{\text {crit }}$ is a constant and is set to the value of $J_{3 \mathrm{~mm}}$. This is demonstrated in Figure 10. The end points of the "fishhooks" lie on the assessment locus defined by $\mathrm{J}_{\text {crit }}=\mathrm{J}_{3 \mathrm{~mm}}$ and the instability crack length is where the end point (tangent) lies on the FAD. This is equivalent to the result for the intersection of the assessment locus and the FAD (see Figure 9). 


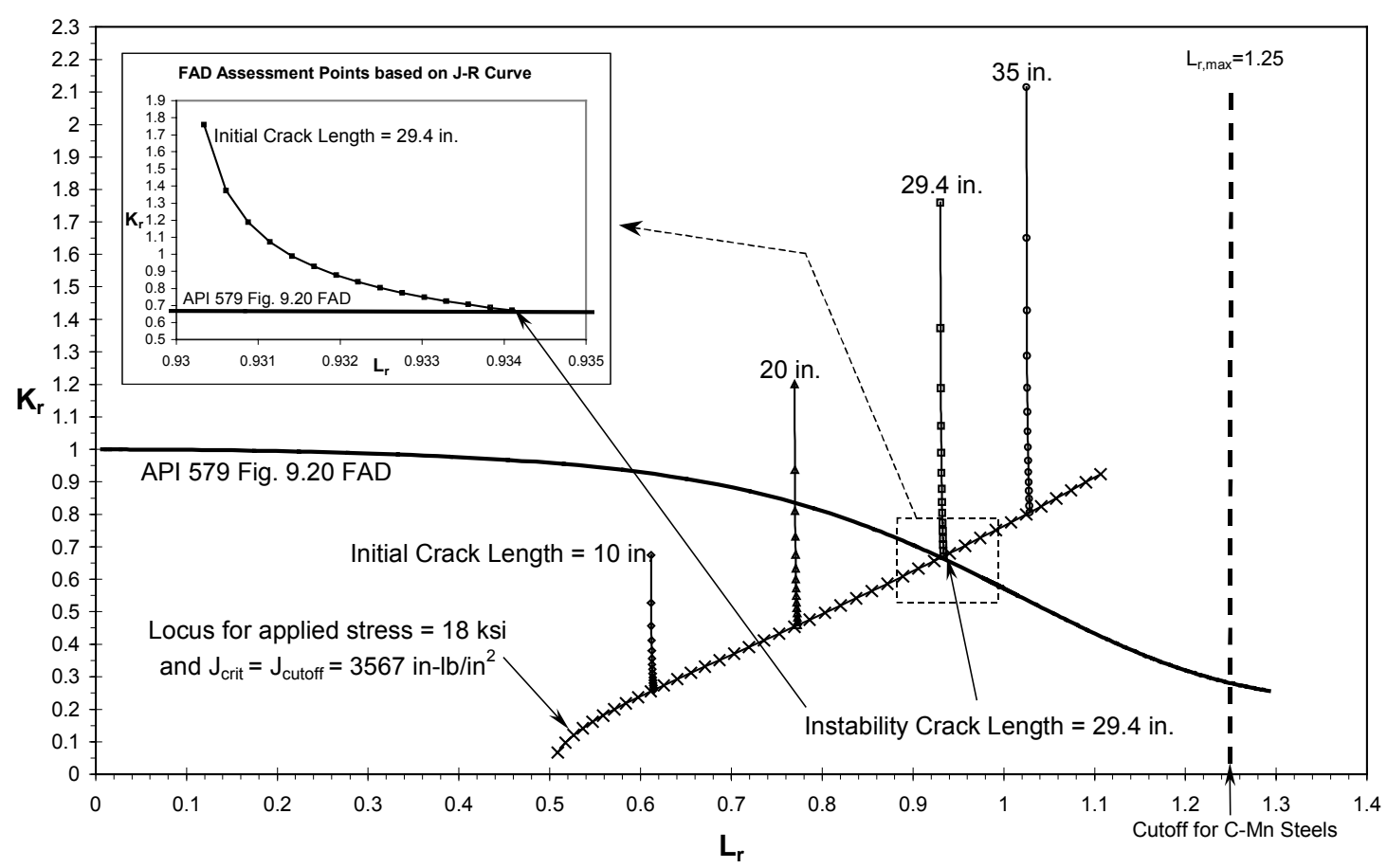

Figure 10. FAD Approach Utilizing J-R Curve Data

\subsection{COMPARISON OF THE INSTABILITY CRACK LENGTHS}

The instability crack lengths determined by J-T and by FAD fracture methodologies are listed in Table 3 ( a subset of Table 1) and Table 4 (same as Table 2) and are plotted in Figures 11 to 14 . It can be seen that when the applied stress is low, the crack instability lengths based on J-T are greater than those determined by FAD, as expected, since the FAD approach generally provides a conservative assessment of flaw stability. However, when the loading is near the yield stress of the material, the results of FAD may overestimate the instability crack length predicted by the J-T method. Note that the J-integral used in the J$\mathrm{T}$ approach in this section was determined by an estimation method based on CCP solution with a curvature correction (Section 4). The finite element method was used in Section 7 of this report to obtain accurate J-integrals for validating the estimated results. It is an industry standard to use approximations or estimation schemes to assess the J-integrals because the finite element method involves building finite element models to analyze cracks in a specific structural configuration and under specific loading conditions. Typical J-integral estimation schemes can be found in Electric Power Research Institute (EPRI) publications [e.g., 28], with which the CCP solution [11] shares the same technical basis. 
Table 3. Instability Crack Lengths for Type I Tank Geometry (inches)

\begin{tabular}{|c|l|c|c|c|c|c|c|c|}
\hline \multirow{2}{*}{$\sigma_{\text {appl }}$} & \multicolumn{4}{|c|}{$\mathrm{J}_{\text {crit }}=\mathrm{J}_{\text {IC }}$} & \multicolumn{5}{c|}{$\mathrm{J}_{\text {crit }}=\mathrm{J}_{3 \mathrm{~mm}}$} \\
\cline { 2 - 9 } & $\mathrm{J}-\mathrm{T}$ & $\begin{array}{c}\text { FAD: } \\
\text { API }\end{array}$ & $\begin{array}{c}\text { FAD: } \\
\sigma-\varepsilon\end{array}$ & $\begin{array}{c}\text { FAD: } \\
\text { R-O }\end{array}$ & $\begin{array}{c}\text { CCP } \\
\mathrm{J}-\mathrm{T}\end{array}$ & $\begin{array}{c}\text { FAD: } \\
\text { API }\end{array}$ & $\begin{array}{c}\text { FAD: } \\
\sigma-\varepsilon\end{array}$ & $\begin{array}{c}\text { FAD: } \\
\text { R-O }\end{array}$ \\
\hline $\begin{array}{c}6 \mathrm{ksi} \\
\left(\sigma_{\mathrm{o}} / 6\right)\end{array}$ & 74.0 & 66.4 & 68.0 & 61.8 & 118.0 & 104.0 & 110.0 & 96.0 \\
\hline $\begin{array}{c}12 \mathrm{ksi} \\
\left(\sigma_{\mathrm{o}} / 3\right)\end{array}$ & 39.7 & 33.0 & 35.0 & 29.0 & 64.2 & 49.6 & 55.0 & 43.2 \\
\hline $\begin{array}{c}18 \mathrm{ksi} \\
\left(\sigma_{\mathrm{o}} / 2\right)\end{array}$ & 23.1 & 20.2 & 22.0 & 17.0 & 40.0 & 29.4 & 32.0 & 25.8 \\
\hline $\begin{array}{c}24 \mathrm{ksi} \\
\left(2 \sigma_{\mathrm{o}} / 3\right)\end{array}$ & 11.4 & 12.8 & 15.0 & 10.2 & 23.8 & 18.8 & 18.6 & 16.8 \\
\hline $\begin{array}{c}30 \mathrm{ksi} \\
\left(5 \sigma_{\mathrm{o}} / 6\right)\end{array}$ & 4.6 & 7.4 & 8.8 & 5.8 & 12.4 & 11.8 & 8.6 & 10.8 \\
\hline $\begin{array}{c}36 \mathrm{ksi} \\
\left(\approx \sigma_{\mathrm{o}}\right)\end{array}$ & 1.8 & 3.6 & 2.2 & 3.0 & 5.6 & 6.6 & 5.8 & 6.8 \\
\hline
\end{tabular}

Table 4. Instability Crack Length for Type II Tank Geometry (inches)

\begin{tabular}{|c|c|c|c|c|c|c|c|c|}
\hline \multirow{2}{*}{$\sigma_{\text {appl }}$} & \multicolumn{4}{|c|}{$\mathrm{J}_{\text {crit }}=\mathrm{J}_{\text {IC }}$} & \multicolumn{5}{c|}{$\mathrm{J}_{\text {crit }}=\mathrm{J}_{3 \mathrm{~mm}}$} \\
\cline { 2 - 9 } & $\begin{array}{c}\text { CCP } \\
\text { J-T }\end{array}$ & $\begin{array}{c}\text { FADI } \\
\text { API }\end{array}$ & $\begin{array}{c}\text { FAD: } \\
\sigma-\varepsilon\end{array}$ & $\begin{array}{c}\text { FAD: } \\
\text { R-O }\end{array}$ & $\begin{array}{c}\text { CCP } \\
\text { J-T }\end{array}$ & $\begin{array}{c}\text { FAD: } \\
\text { API }\end{array}$ & $\begin{array}{c}\text { FAD: } \\
\sigma-\varepsilon\end{array}$ & $\begin{array}{c}\text { FAD: } \\
\text { R-O }\end{array}$ \\
\hline $\begin{array}{c}6 \mathrm{ksi} \\
\left(\sigma_{\mathrm{o}} / 6\right)\end{array}$ & 82.4 & 73.2 & 74.9 & 68.8 & 131.7 & 118.2 & 124.1 & 109.2 \\
\hline $\begin{array}{c}12 \mathrm{ksi} \\
\left(\sigma_{\mathrm{o}} / 3\right)\end{array}$ & 43.9 & 36.6 & 39.2 & 32.4 & 71.3 & 56.0 & 61.8 & 48.6 \\
\hline $\begin{array}{c}18 \mathrm{ksi} \\
\left(\sigma_{\mathrm{o}} / 2\right)\end{array}$ & 25.0 & 22.6 & 24.9 & 18.8 & 44.1 & 33.6 & 39.9 & 29.0 \\
\hline $\begin{array}{c}24 \mathrm{ksi} \\
\left(2 \sigma_{\mathrm{o}} / 3\right)\end{array}$ & 11.8 & 14.0 & 16.9 & 11.0 & 25.7 & 21.4 & 22.5 & 18.6 \\
\hline $\begin{array}{c}30 \mathrm{ksi} \\
\left(5 \sigma_{\mathrm{o}} / 6\right)\end{array}$ & 4.6 & 8.0 & 10 & 6.2 & 12.9 & 13.4 & 11.0 & 12.0 \\
\hline $\begin{array}{c}36 \mathrm{ksi} \\
\left(\approx \sigma_{\mathrm{o}}\right)\end{array}$ & 1.8 & 3.8 & 2.4 & 3.2 & 5.7 & 7.4 & 6.2 & 3.6 \\
\hline
\end{tabular}




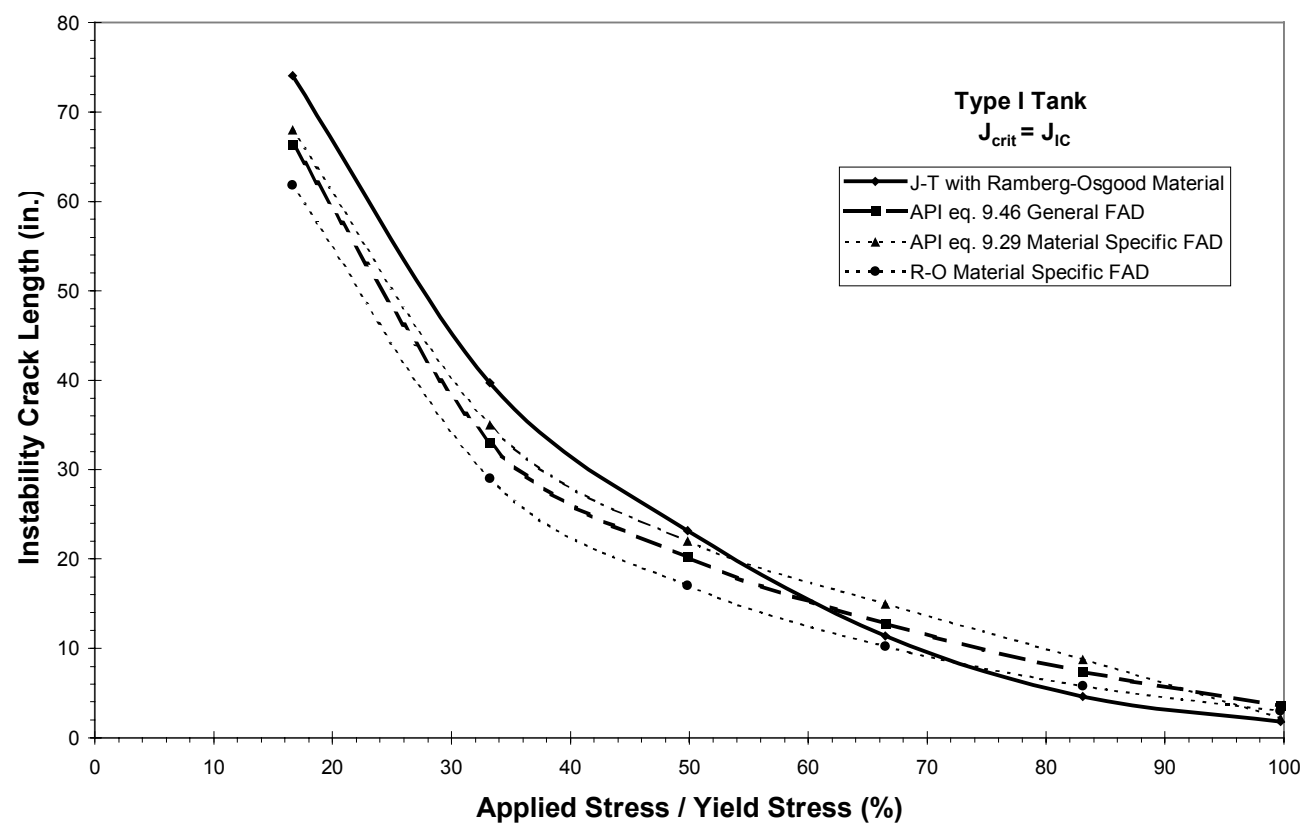

Figure 11. Comparison of Predicted Instability Crack Length with $\mathbf{J}_{\text {crit }}=\mathbf{J}_{I C}$ for Type I Tanks

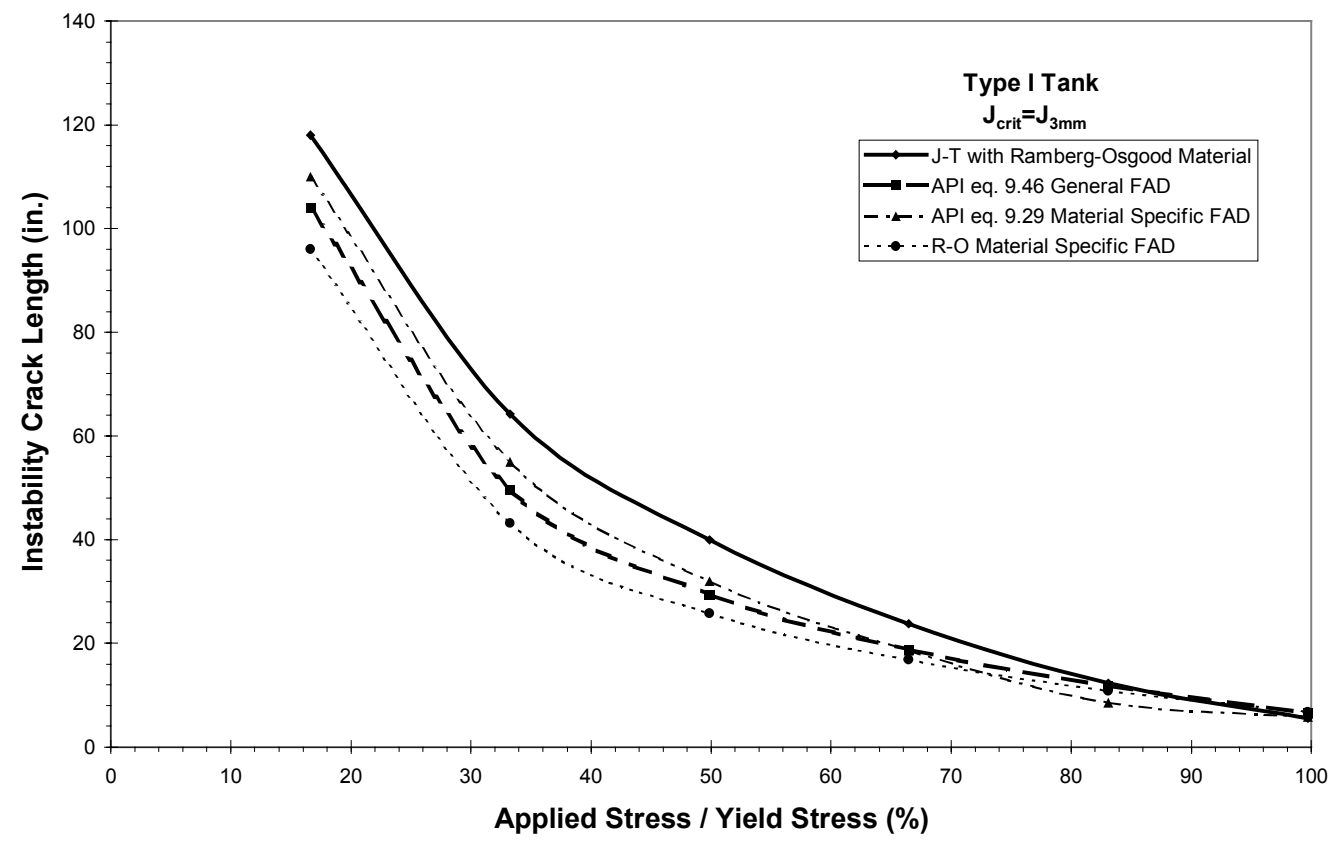

Figure 12. Comparison of Predicted Instability Crack Length with $\mathbf{J}_{\text {crit }}=\mathbf{J}_{3 \mathrm{~mm}}$ for Type I Tanks 


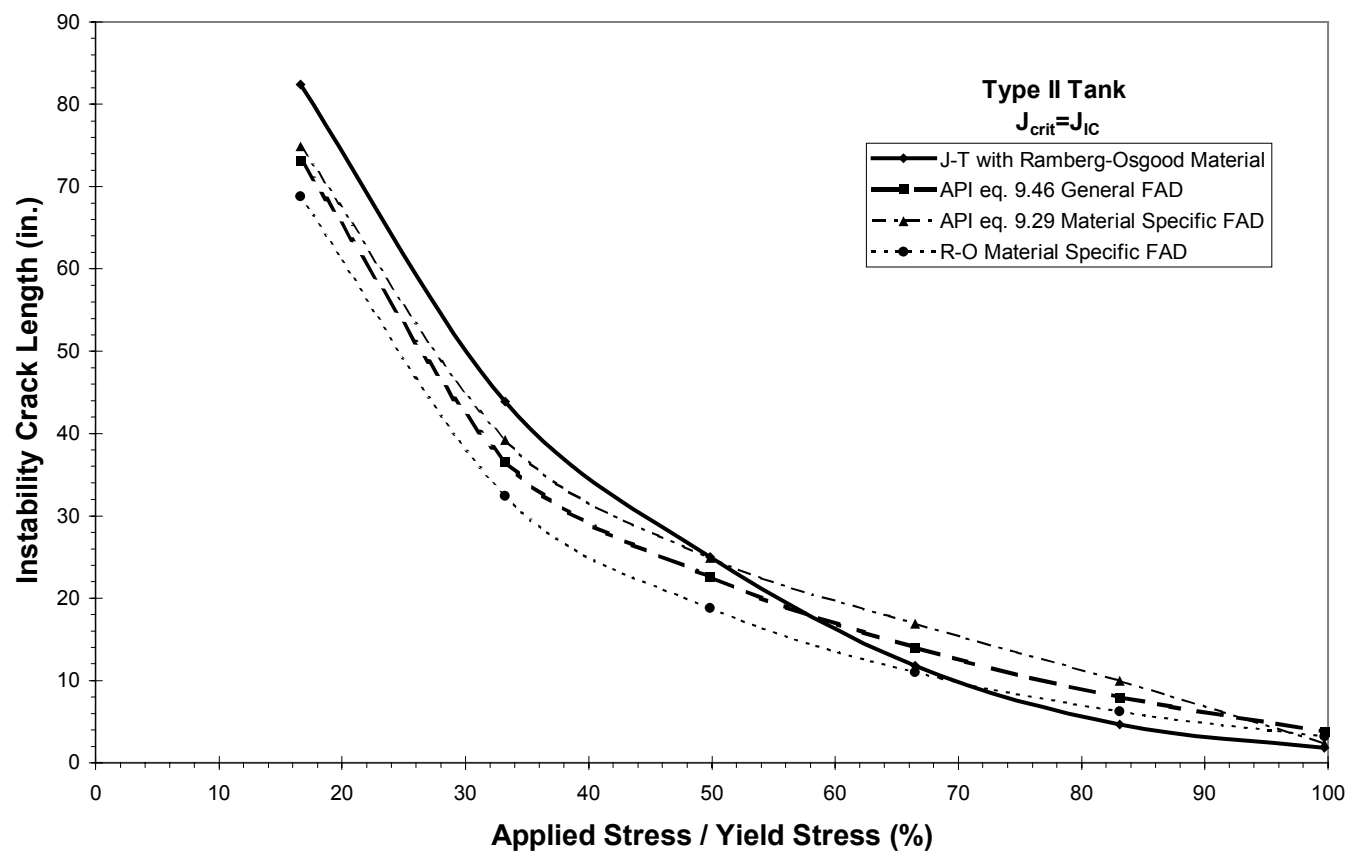

Figure 13. Comparison of Predicted Instability Crack Length with $\mathbf{J}_{\text {crit }}=\mathbf{J}_{I C}$ for Type II Tanks

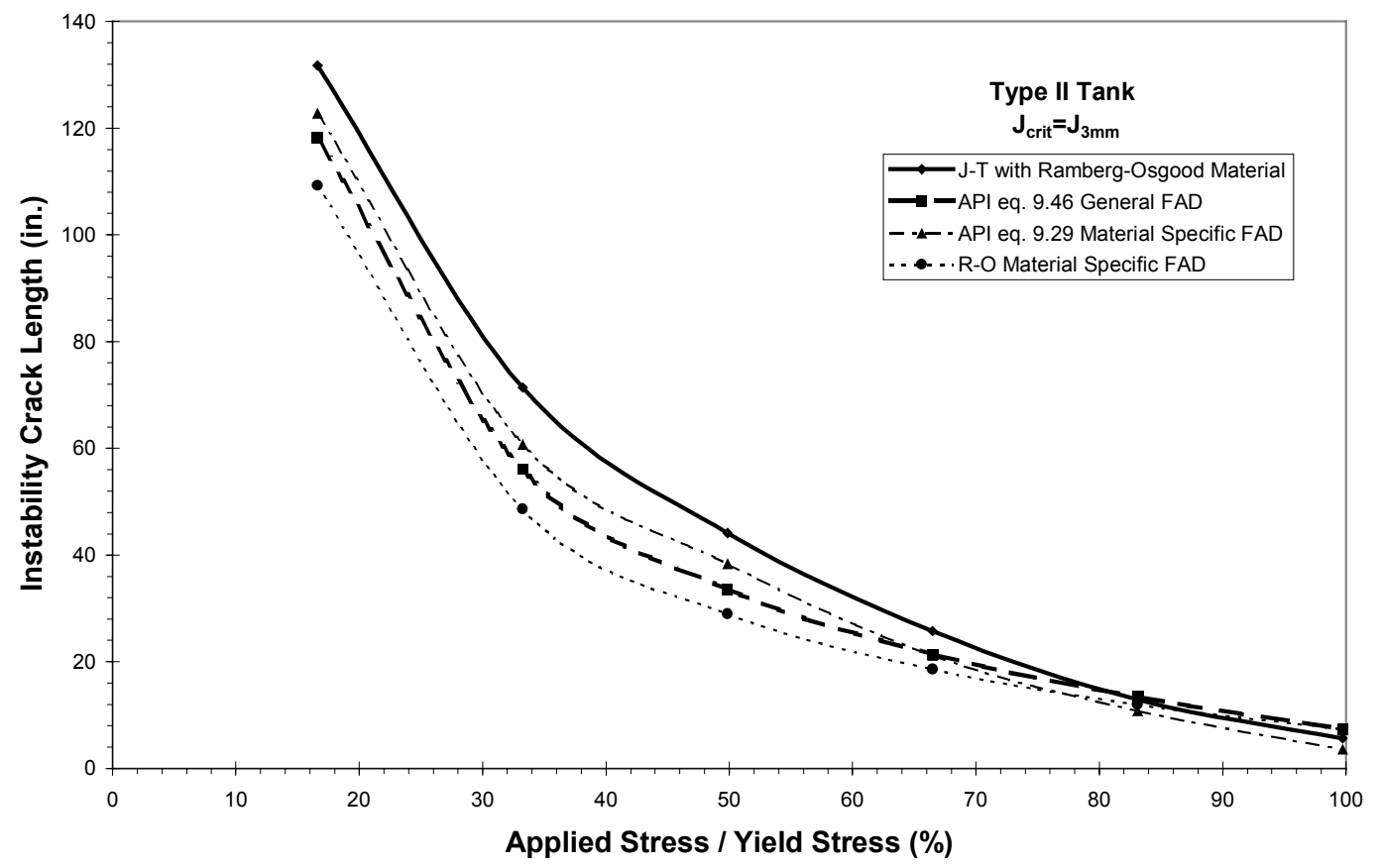

Figure 14. Comparison of Predicted Instability Crack Length with $\mathbf{J}_{\text {crit }}=\mathbf{J}_{3 \mathrm{~mm}}$ for Type II Tanks 
The same conclusion can be drawn from Figures 15 and 16. In these figures, the Jintegral is normalized by $t \sigma_{o}$ and the instability crack length $\left(\mathrm{a}_{\text {crit }}\right)$ is normalized by the plate or shell thickness ( $\mathrm{t})$. The comparisons are made between the J-T crack lengths and the FAD crack lengths assessed from two $J_{\text {crit }}$ values ( $J_{I C}$ and $J_{3 \mathrm{~mm}}$, respectively). It can be seen that the FAD solutions are not always conservative with respect to the J-T solution. For example, in Figure 15 (Type I tank) when the applied stress is $2 / 3$ of the yield stress and $\mathrm{J}_{\mathrm{IC}}$ is used as the fracture criterion, both failure assessment diagrams (the general FAD and the material-specific FAD) show higher crack lengths than the J-T results. When $\mathrm{J}_{3 \mathrm{~mm}}$ is chosen for the fracture criterion, FAD results are mostly conservative, especially when the material-specific FAD is used. Similar observations are described in Reference 16.
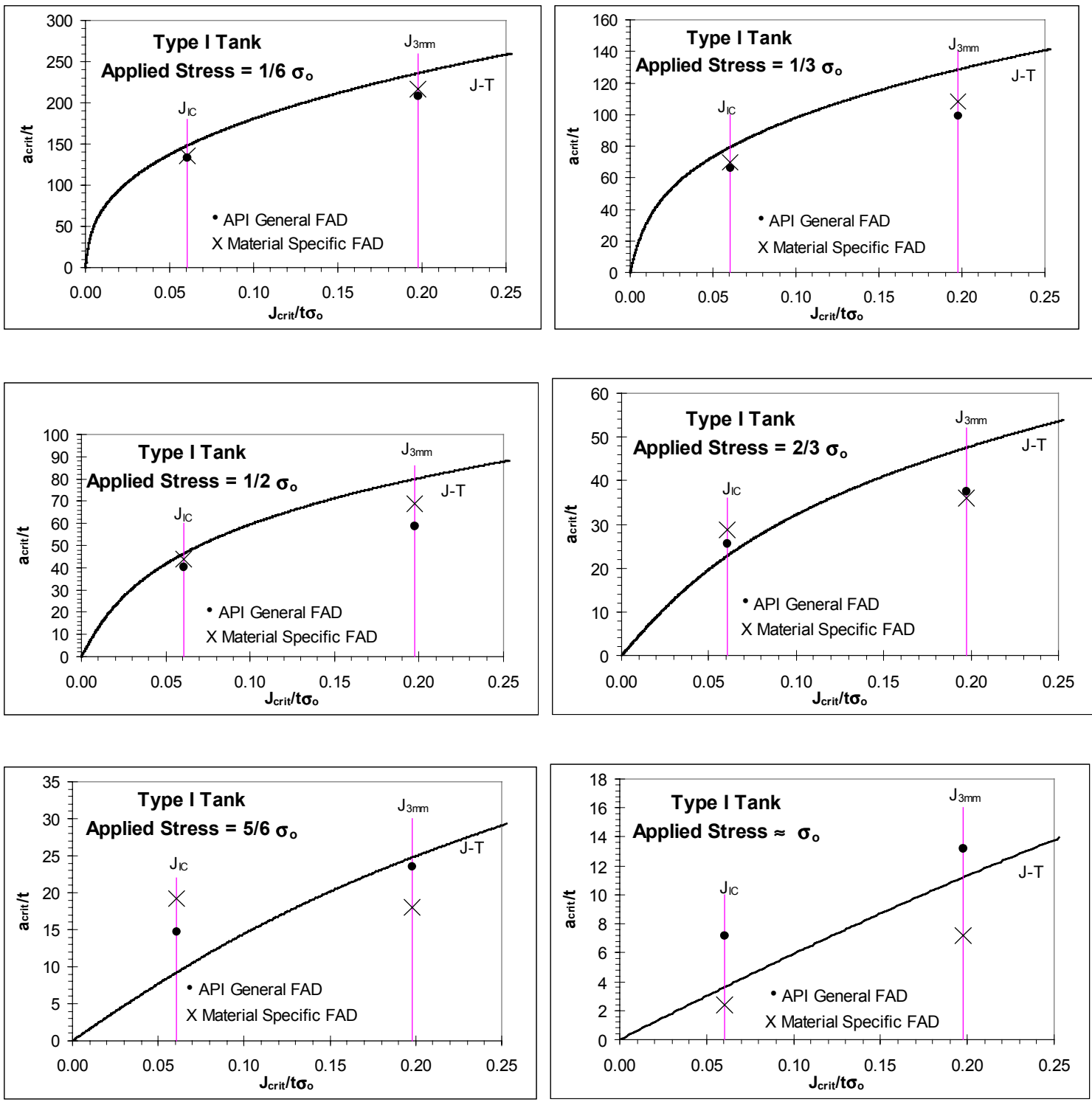

Figure 15. Comparison of Predicted Instability Crack Lengths from J-T and FAD for Given $\mathbf{J}_{\text {crit }}$ in Type I Tanks 

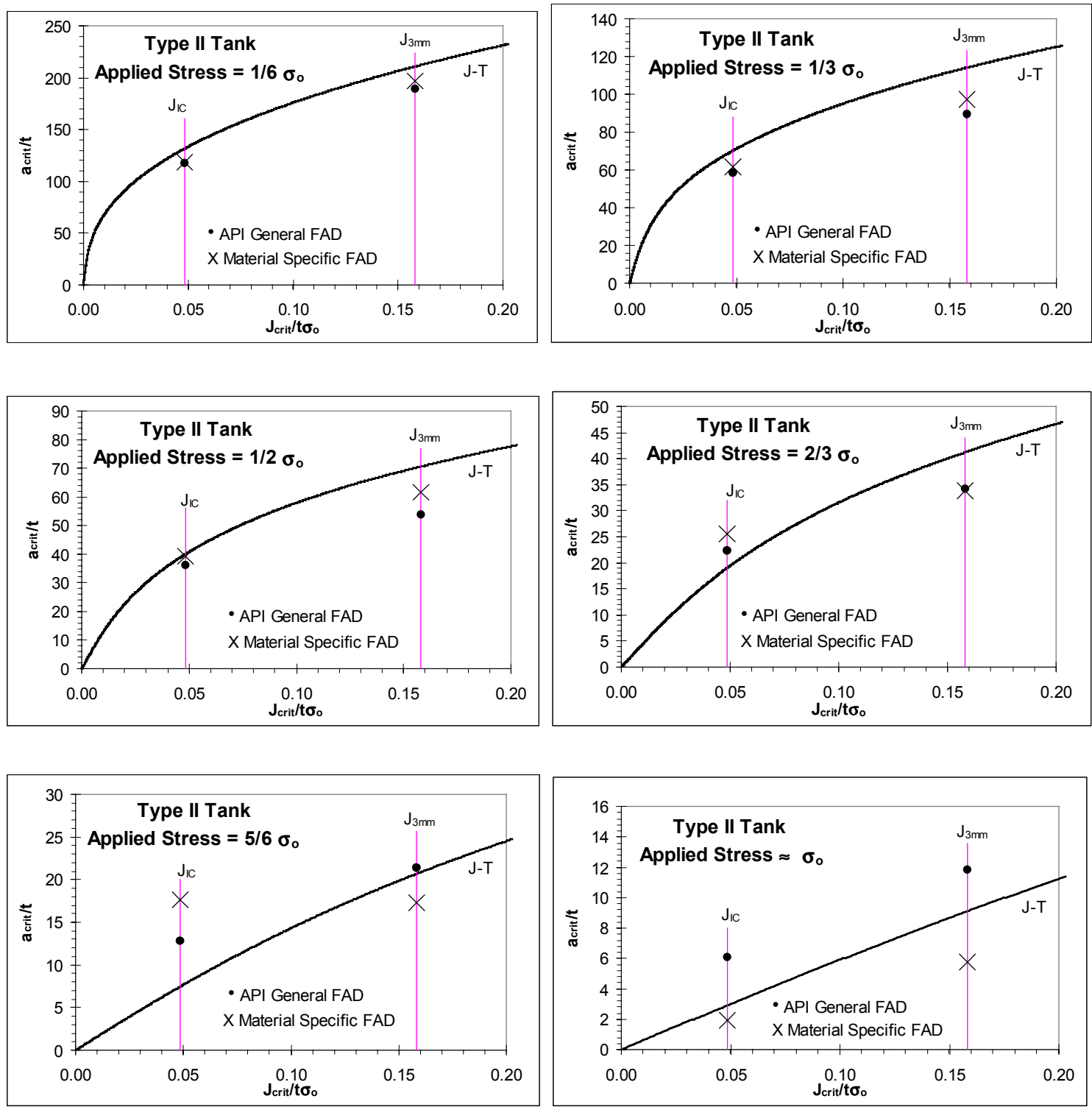

Figure 16. Comparison of Predicted Instability Crack Lengths from J-T and FAD for Given $\mathbf{J}_{\text {crit }}$ in Type II Tanks

\subsection{FINITE ELEMENT VALIDATION}

The finite element method was used to assess the degree of validity of the CCP solution with curvature correction (Section 4). In addition, the numerical results were used to construct failure assessment diagrams based on API 579 recommendation [7] and to establish equivalency between J-T and FAD fracture methodologies. 


\subsection{Finite Element Modeling}

The Type I waste tank ( 75 feet in diameter, 24.5 feet in height, and 0.5 inches in wall thickness) was used as a typical geometry in the analyses. A through-wall axial crack is assumed to exist in the mid-tank location. Due to symmetry, only a quarter of the tank is modeled as shown in the overall finite element mesh in Figure 17. This model contains 1893 eight-noded shell elements (ABAQUS [31] Element Type S8R5) and 5880 nodes. It was optimized to accommodate five crack configurations (crack lengths: 10, 20,30, 40 ,and 50 inches). This allows separate analysis be performed for each crack size with the same finite element mesh; only the boundary conditions were modified for the respective crack length. The finite elements were heavily refined in the cracked region and highly concentrated near the crack tips. Around each crack tip, at least five J-integral contour integrations could be performed (Fig. 18). In general, the J-integral value from the first contour is inaccurate. The J-integrals reported in this report were the average of the rest of the four contour integral values.

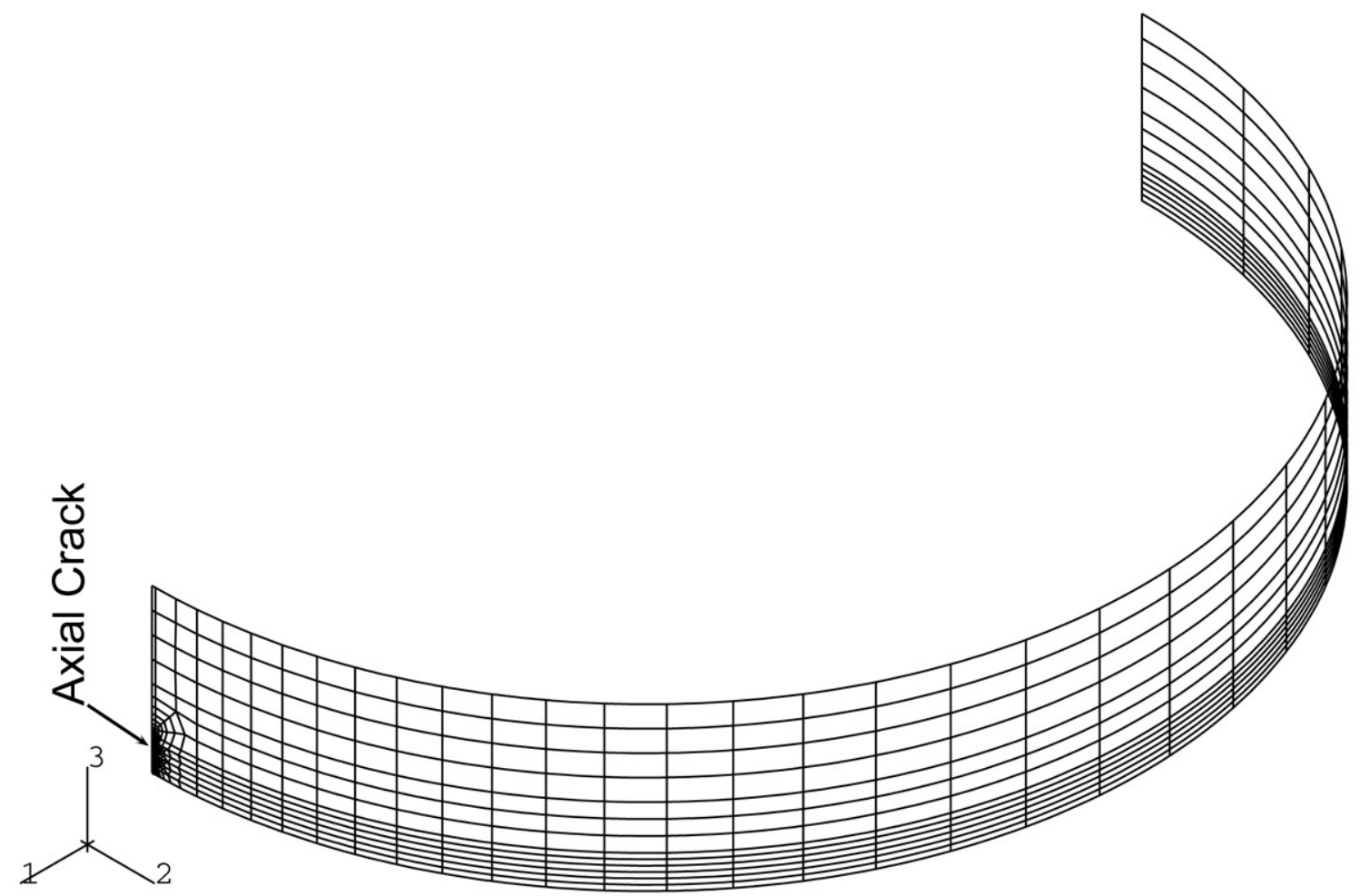

Figure 17. Finite Element Mesh for Type I Waste Tank Containing an Axial Crack 

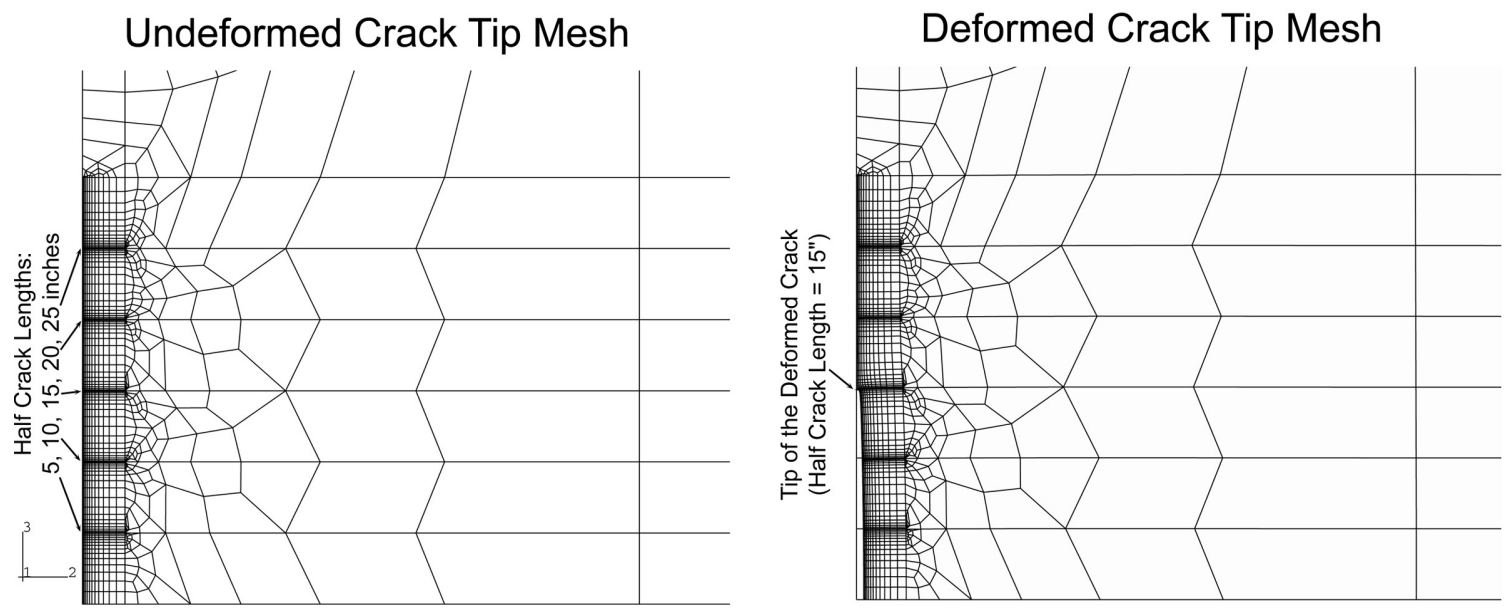

Figure 18. Near Crack Tip Mesh Design and a Typical Deformed Shape

The tank material is A285 Grade B and its tensile properties were determined in Reference 9. Two material responses were used: 1) actual stress-strain test data (Fig.1) with incremental plasticity; and 2) Ramberg-Osgood stress-strain law (see Fig. 1, n=5.0, $\alpha=3.2$ ) and deformation plasticity. The uniform hoop stress was generated by imposing internal pressure to the tank wall. Note that the ABAQUS shell element formulation excludes the pressure loading to the J-integral calculation, but all the in-plane stresses are included. That is, the local bending caused by the bulging of the flawed area resulted from the internal pressure is ignored. However, this is exactly the case in the present analysis, which compares the instability crack lengths for an axial crack under hoop stress only. The typical deformation near a crack tip is also shown in Figure 18.

\subsection{Accuracy of the CCP Solution}

A linear elastic solution with $E=30,000 \mathrm{ksi}, \sigma_{\mathrm{o}}=36.1 \mathrm{ksi}$, and $v=0.3$ was performed with the finite element model shown in Figure 17. The J-integral obtained in this analysis is the elastic portion of the J-integral which is proportion to the square of the applied stress. This quantity can be compared with the curvature-corrected first term of the CCP solution (see Section 4):

$\mathrm{J}_{\mathrm{el}}^{\mathrm{cur}}=\mathrm{Y}^{2} \mathrm{~J}_{\mathrm{el}}^{\mathrm{ccp}}=\mathrm{Y}^{2} \Psi \sigma_{\mathrm{o}} \varepsilon_{\mathrm{o}} \mathrm{a}\left(1-\frac{\mathrm{a}}{\mathrm{b}}\right)\left(\frac{\mathrm{P}}{\mathrm{P}_{\mathrm{o}}}\right)^{2} \mathrm{~g}_{1}\left(\frac{\mathrm{a}_{\text {eff }}}{\mathrm{b}}, \mathrm{n}=1\right)$,

where the symbols can be found in Section 4.3 and $\mathrm{Y}$ is an appropriate curvature correction factor calculated according to Section 4.4. It can be seen in Figure 19 that the estimated (labeled with CCP) and the finite element (labeled with FEA) solutions agree very well. 


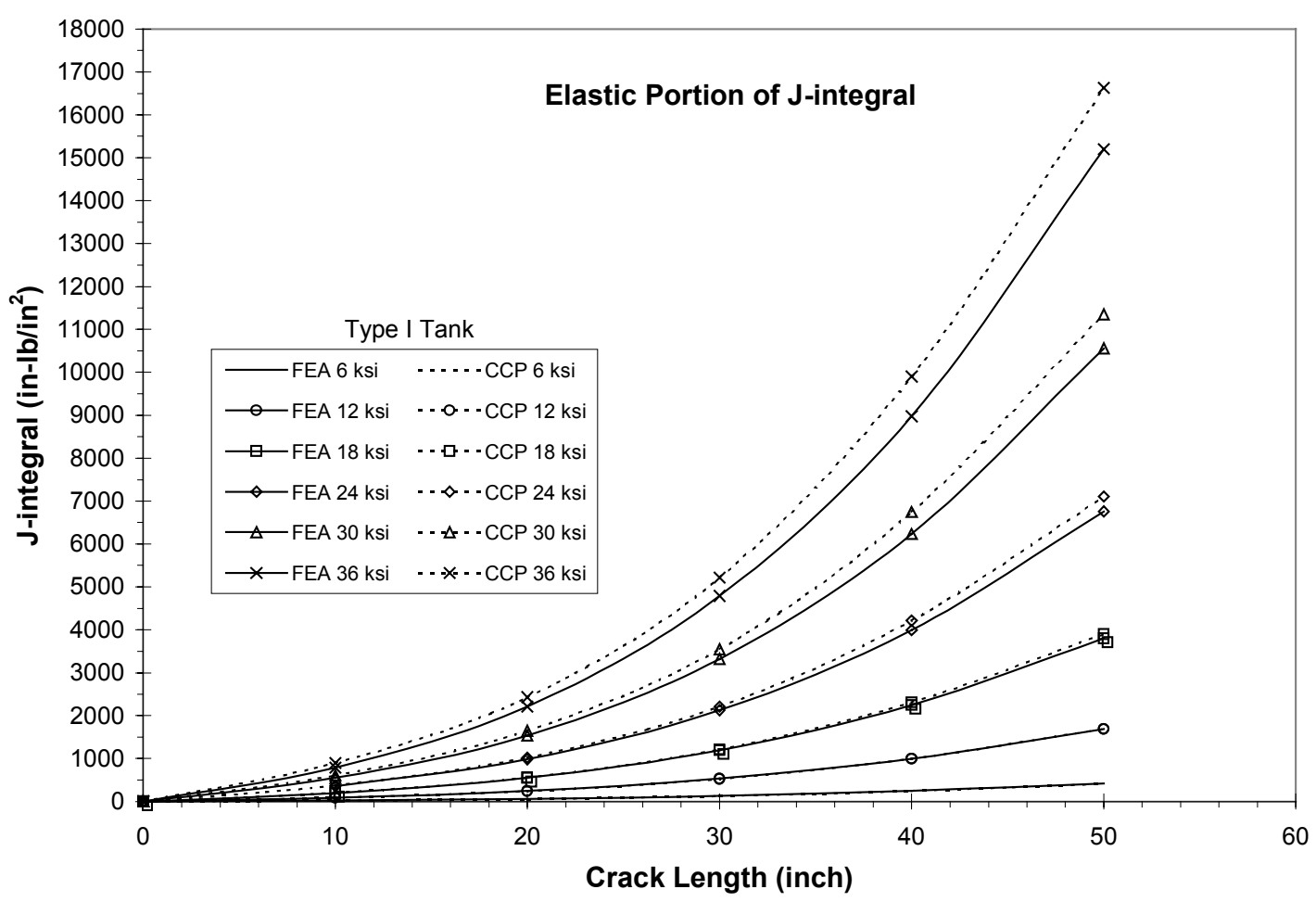

Figure 19. Comparison of the Elastic Portion of the J-integral Solutions

The total J-integral was also calculated for elastic-plastic deformation. Two constitutive formulations were used. To be closely compare to the estimated solution (CCP), the same Ramberg-Osgood stress-strain law (Fig. 1) was input to the finite element code [31] and the mechanical response was calculated with the deformation theory of plasticity. The finite element results based on this formulation are labeled as "FEA R-O" in the subsequent figures. alternatively, stress-strain data (Fig. 1) from material testing [9] could also be input to the finite element code. This type of elastic-plastic analysis employs the incremental theory of plasticity. The results are labeled with "FEA el-pl" in the figures. The values of total J-integral obtained from the estimation method (CCP) and from the finite element analyses (FEA R-O and FEA el-pl) are plotted in Figure 20. As expected, under low applied stress levels and for small crack length configurations, all the solutions are very similar. In addition, it shows a well-known trend that the incremental plasticity predicts a more rigid material response. The discrepancy among the solutions increases as either the applied hoop stress or the crack length increases. The J-integrals calculated with the CCP estimation method are very close to those based on incremental plasticity (Fig. 20), especially in cases where the applied stress is less than 18 ksi ( $50 \%$ of the $0.2 \%$ yield stress). 


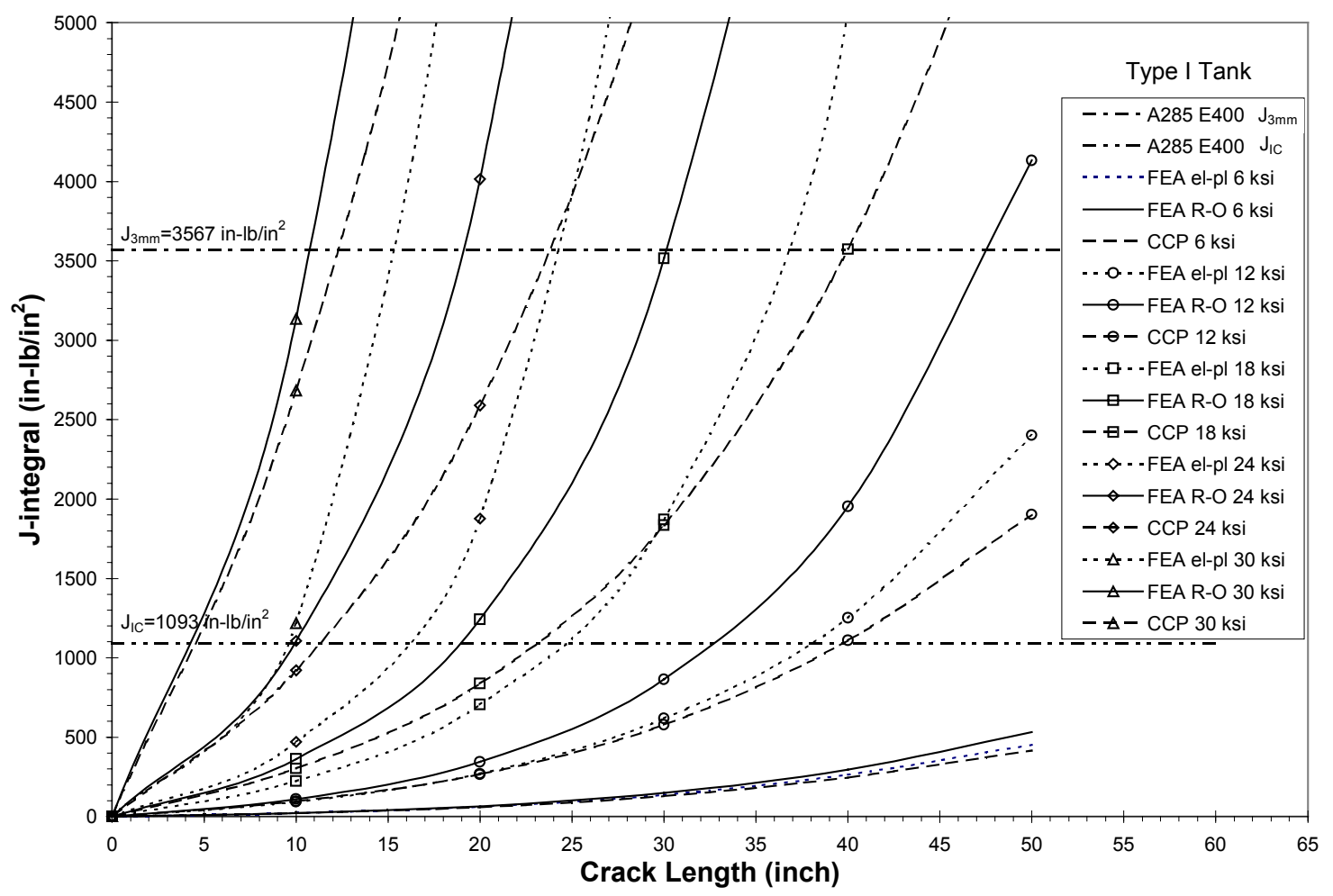

Figure 20. Comparison of the Solutions for Total J-integral

\subsection{Comparison of the Instability Crack Lengths}

Figure 20 was used to obtain the finite-element-based instability crack lengths using the $\mathrm{J}-\mathrm{T}$ fracture methodology with the critical $\mathrm{J}$ values $\left(\mathrm{J}_{\text {crit }}\right)$ set to $\mathrm{J}_{\mathrm{IC}}\left(1093 \mathrm{in}-\mathrm{lb}_{\mathrm{in}}{ }^{2}[10]\right)$ and to $\mathrm{J}_{3 \mathrm{~mm}}\left(3567 \mathrm{in}-\mathrm{lb} / \mathrm{in}^{2}[10]\right)$, respectively. Some instability crack lengths under high applied stress required extrapolation because the finite element mesh (Figs. 17 and 18) was not explicitly designed for cracks less than 10 inches long. Table 5 (same as Table 1) summarizes the instability crack lengths resulted from all the fracture methodologies in this study for the Type I waste tank configuration. The graphic representations of Table 5 are show in Figure 21 for $\mathrm{J}_{\text {crit }}=\mathrm{J}_{\mathrm{IC}}$ and in Figure 22 for $\mathrm{J}_{\text {crit }}=\mathrm{J}_{3 \mathrm{~mm}}$. 
Table 5. Instability Crack Lengths based on Various Fracture Methodologies (Type I Tank)

\begin{tabular}{|c|c|c|c|c|c|c|c|c|c|c|c|c|}
\hline \multirow{5}{*}{$\begin{array}{l}\sigma_{\text {appl }} \\
\text { (ksi) }\end{array}$} & \multicolumn{12}{|c|}{ Summary of Type I Tank Instability Crack Lengths (inches) } \\
\hline & \multicolumn{6}{|c|}{$\mathrm{J}_{\text {crit }}=\mathrm{J}_{\mathrm{IC}}$} & \multicolumn{6}{|c|}{$\mathrm{J}_{\text {crit }}=\mathrm{J}_{3 \mathrm{~mm}}$} \\
\hline & $\mathrm{J}-\mathrm{T}$ & $\mathrm{J}-\mathrm{T}$ & $\mathrm{J}-\mathrm{T}$ & FAD & FAD & FAD & $\mathrm{J}-\mathrm{T}$ & $\mathrm{J}-\mathrm{T}$ & $\mathrm{J}-\mathrm{T}$ & FAD & FAD & FAD \\
\hline & $\mathrm{CCP}$ & FEA & FEA & & & & $\mathrm{CCP}$ & FEA & FEA & & & \\
\hline & $\mathrm{R}-\mathrm{O}$ & $\mathrm{R}-\mathrm{O}$ & $\sigma-\varepsilon$ & API & $\sigma-\varepsilon$ & $\mathrm{R}-\mathrm{O}$ & $\mathrm{R}-\mathrm{O}$ & $\mathrm{R}-\mathrm{O}$ & $\sigma-\varepsilon$ & API & $\sigma-\varepsilon$ & $\mathrm{R}-\mathrm{O}$ \\
\hline 6 & 74.0 & 67.0 & 71.0 & 66.4 & 68.0 & 61.8 & 118.0 & 110. & 114. & 104. & 110. & 96.0 \\
\hline 12 & 9.7 & 32.8 & 38.0 & 33.0 & 35.0 & 29.0 & 64.2 & 47.5 & 56.8 & 49.6 & 55.0 & 43.2 \\
\hline 18 & 3.1 & 19.0 & 24.8 & 20.2 & 22.0 & 17.0 & 40.0 & 30.1 & 36.9 & 29.4 & 32.0 & 25.8 \\
\hline 24 & 11.4 & 10.0 & 16.7 & 12.8 & 15.0 & 10.2 & 23.8 & 19.1 & 24.4 & 18.8 & 18.6 & 16.8 \\
\hline 30 & 4.6 & 4.6 & 10.0 & 7.4 & 8.8 & 5.8 & 12.4 & 10.8 & 16.3 & 11.8 & 8.6 & 10.8 \\
\hline 36 & 1.8 & 4.0 & \begin{tabular}{|l|l|}
7.4 \\
\end{tabular} & 3.6 & 2.2 & 3.0 & 5.6 & 6.4 & 6.7 & 6.6 & 5.8 & 6.8 \\
\hline
\end{tabular}

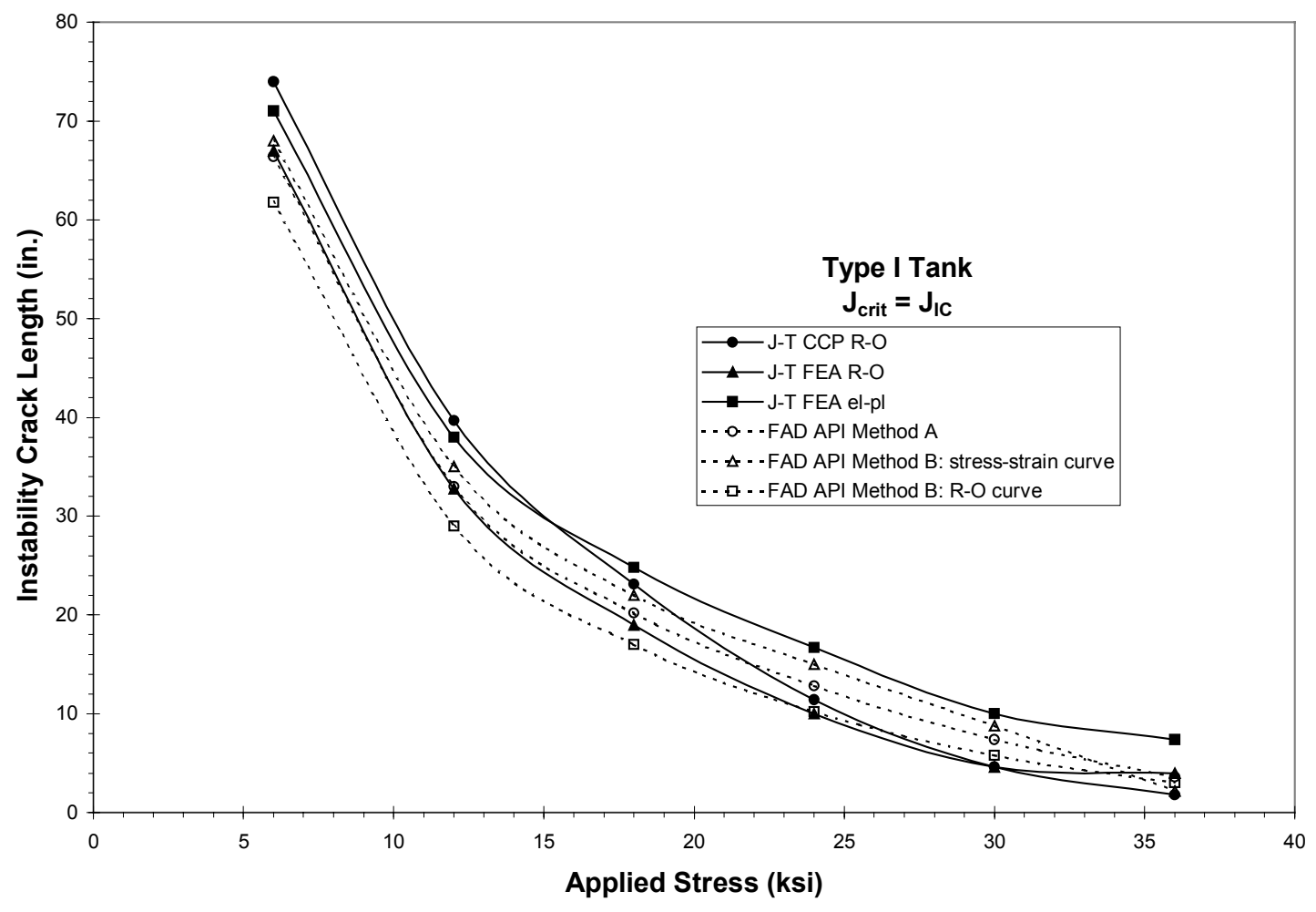

Figure 21. Type I Tank Instability Crack Lengths Resulted from Various Fracture Methodologies when $\mathbf{J}_{\text {crit }}=\mathbf{J}_{\mathbf{I C}}$. 


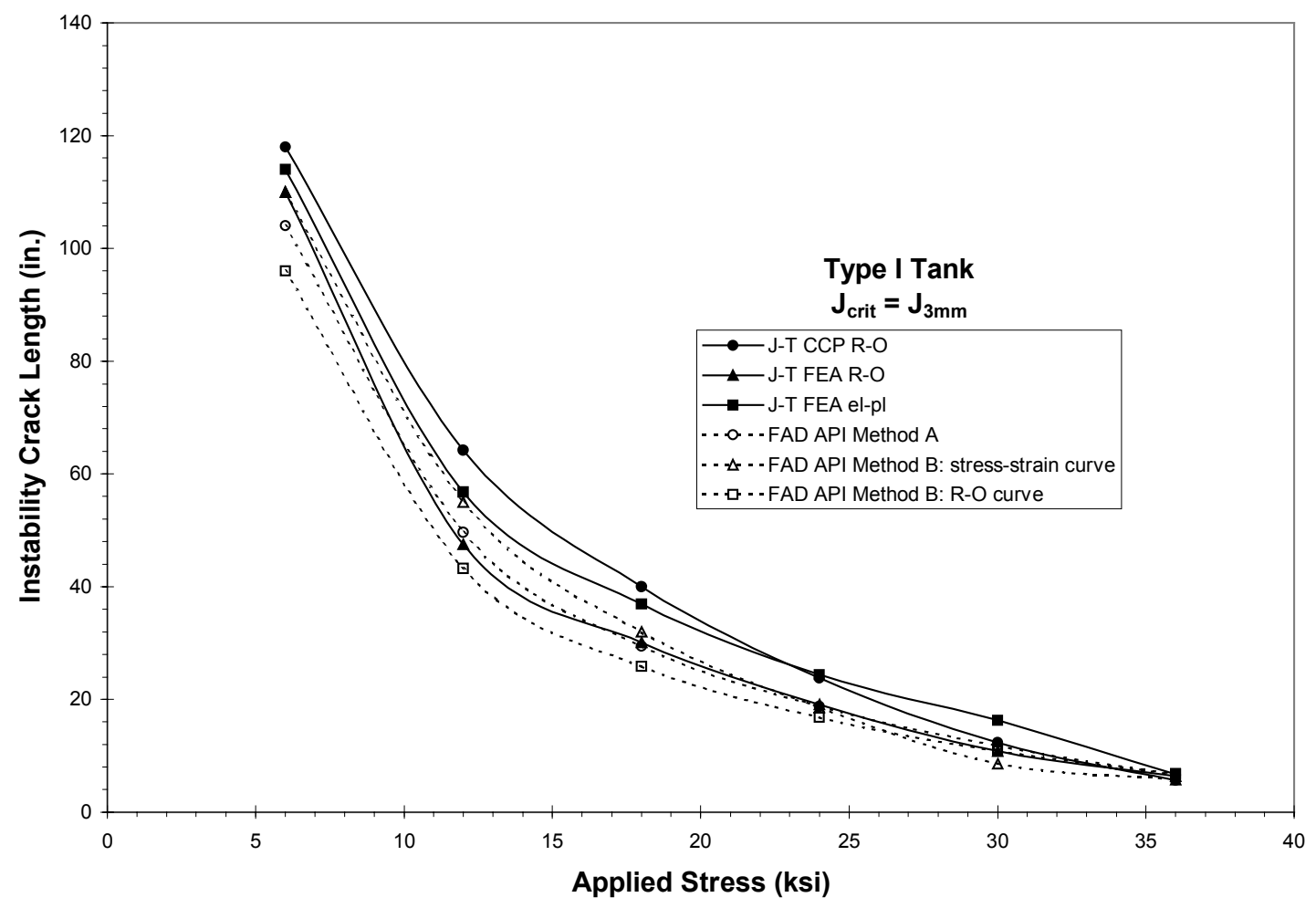

Figure 22. Type I Tank Instability Crack Lengths Resulted from Various Fracture Methodologies when $\mathbf{J}_{\text {crit }}=\mathbf{J}_{3 \mathrm{~mm}}$

\subsection{Finite-Element-Based Failure Assessment Diagrams}

Similar to the FAD formulations with the strip yield model [27] or with the J-integral estimation scheme [29], the FAD can be constructed numerically with the finite element method. In general, the J-based FAD is crack length-dependent. The simplicity of the strip yield FAD [27] (a single curve in the $\mathrm{L}_{\mathrm{r}}-\mathrm{K}_{\mathrm{r}}$ space) is lost as discussed in Sections 5.1 and 5.2 of this report. However, it was found that a reference stress could be properly chosen so that the FAD may be insensitive to the crack length. The procedure is described in API 579 Appendix B [7] and also in References 30 and 32.

As discussed earlier, the coordinates of the FAD $\left(K_{r}\right.$ and $\left.L_{r}\right)$ are defined as $K_{r}=\sqrt{\frac{J^{e}}{J}}$ and $\mathrm{L}_{\mathrm{r}}=\frac{\mathrm{P}}{\mathrm{P}_{\text {ref }}}$, where $\mathrm{J}^{\mathrm{e}}$ is the elastic portion of $\mathrm{J}$ and can be obtained by an elastic analysis (Fig. 19), $\mathrm{J}$ is the total J-integral (Fig. 20) which is the sum of its elastic portion and the plastic portion, $\mathrm{P}$ is the applied load (or stress), and $\mathrm{P}_{\text {ref }}$ is the reference load (or stress). For each flaw configuration, $\mathrm{P}_{\text {ref }}$ is calculated according to 


$$
\left.\frac{\mathrm{J}}{\mathrm{J}^{\mathrm{e}}}\right|_{\mathrm{p}=\mathrm{p}_{\mathrm{ref}}}=1+\frac{0.002 \mathrm{E}}{\sigma_{\mathrm{o}}}+\frac{1}{2}\left(1+\frac{0.002 \mathrm{E}}{\sigma_{\mathrm{o}}}\right)^{-1} .
$$

With this crack length-dependent $P_{\text {ref }}$ (Fig. 23), the finite-element-based failure assessment diagrams can be collapsed to roughly a single curve for each of the two families of curves as demonstrated in Figure 24. Note that in Figure 24, the coordinates of the common point for all the curves have been determined by Eq. 12 .

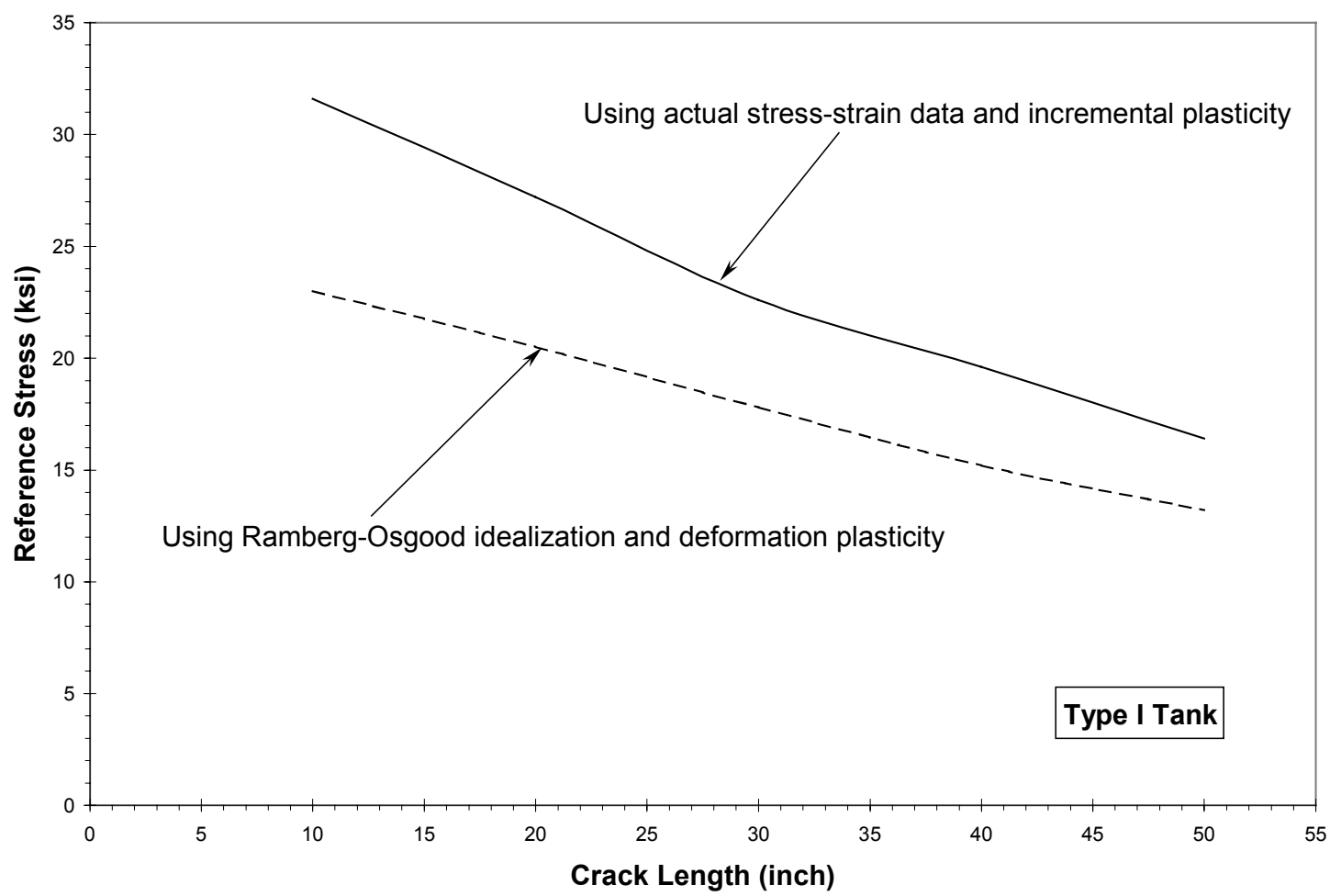

Figure 23. Crack Length-Dependent Reference Loads for Type I Tank with an Axial Flaw

Two families of curves can be seen in Figure 24: one was obtained with the RambergOsgood power law (Eq. 2 or Fig. 1) and using the deformation plasticity; and the other was obtained by inputting stress-strain test data (Fig. 1) and employing the incremental plasticity. A typical FAD from each group in Figure 24 was selected and plotted in Figure 8, Section 5.3, along with the other failure assessment diagrams. It can be seen in Figure 8 that these three failure assessment diagrams are almost on top of each other: 1) the Dugdale strip yield model [27]; 2) the Equation 9.46 in the API 579 First Edition [7] for Level 3 Method A Assessment (or CEGB R6 Option 1); and 3) the finite element results with the actual stress-strain curve for the API 579 Level 3 Method C Assessment [7]. Because of this similarity, the instability crack lengths based on the finite element FAD were not calculated. It is expected that the above conclusions are also valid for 
Type II tanks. Therefore, the finite element analysis for Type II tank configuration was not performed.

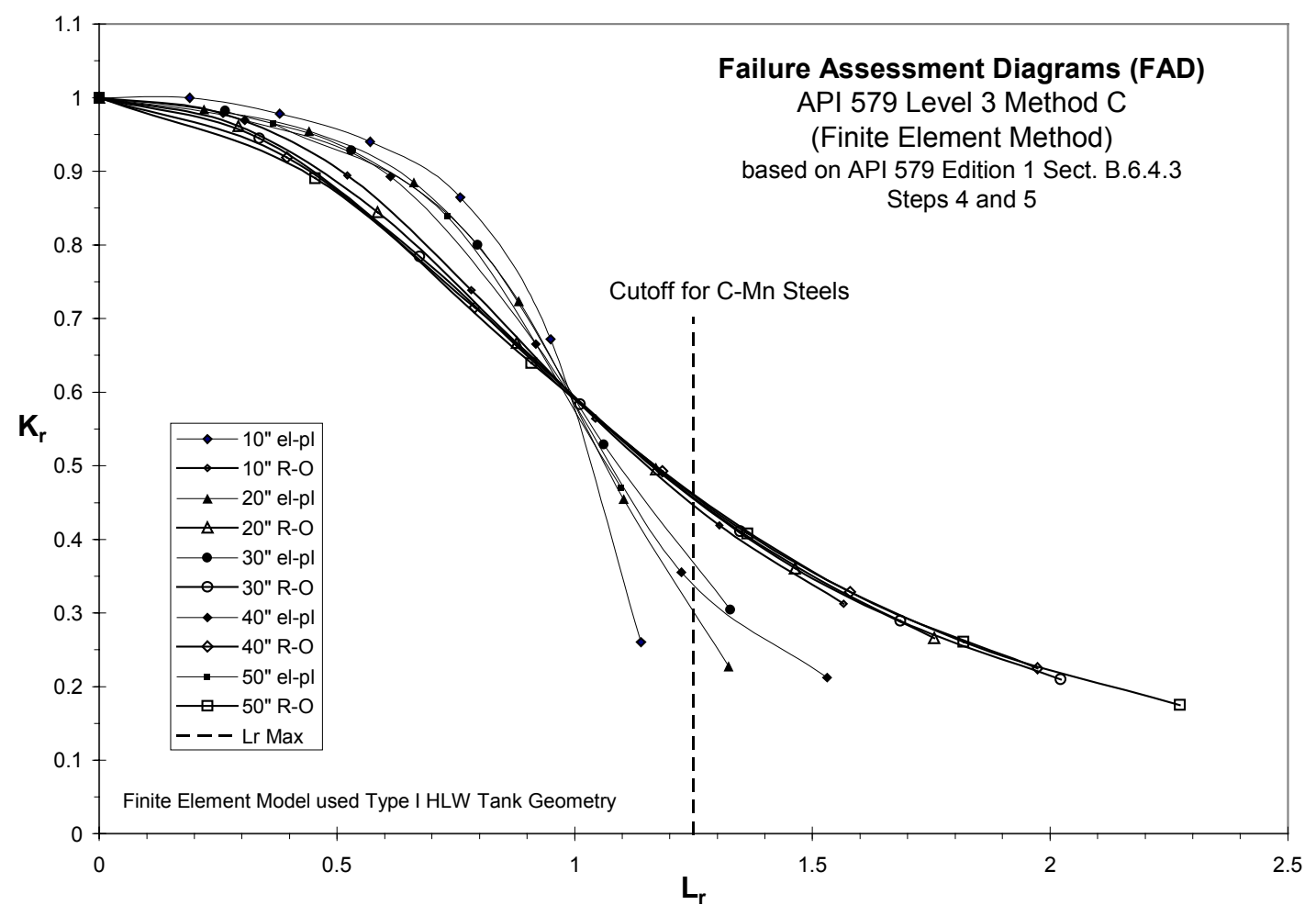

Figure 24. Finite-Element-Based Failure Assessment Diagrams

\subsection{Software QA Control}

The ABAQUS finite element software code [31] has been used in the validation analyses. This software code meets the Savannah River Site (SRS) QA requirements (1Q,QAP 201) [33]. The Information Technology Department at the SRS is responsible for installation and maintenance of this code on the SRS UNIX systems. The Engineering Development Section of Savannah River Technology Center (SRTC) is the software custodian and is responsible for distributing the error reports from the vendor (Hibbitt, Karlsson \& Sorensen, Inc.) to the SRS users. There are no errors affecting the analyses in this report. The input files for the analyses have been archived for permanent storage.

\subsection{FRACTURE METHODOLOGY REFINEMENT}

The fracture toughness of a material is known to be test specimen size-dependent. For deep cracks, the plastic zone at the tip of the crack is limited by the specimen uncracked ligament. However, for short or shallow cracks the plasticity is relatively unconstrained. 
In general, the testing of high constraint specimens yields lower J-R curves that would result in shorter instability crack lengths. In the SRS waste tank configurations, most of the flaws are less constrained than the mechanical test specimens (e.g., ASTM compact tension specimens). Therefore, the prediction of instability crack length with the fracture toughness based on the ASTM plane strain specimens may be overly conservative.

More accurate fracture toughness or J-R curves can be obtained by identifying an additional fracture parameter based on the constraint theories of fracture mechanics. To determine the additional parameter, finite element analyses of the specimens and the large structure (e.g., waste tank) with a flaw should be performed. Specimens with various crack lengths are tested to establish the functional dependence of the J-R curves on the additional fracture parameter. For example, Reference 34 used a J-A theory [35-37] $\left(\mathrm{A}_{2}\right.$ is the additional fracture parameter characterizing the constraint level) and showed that the experimental J-R curves [38] with different initial crack lengths could be predicted.

A similar approach using three-point bend specimens as the test specimen design for the SRS waste tank structural integrity has been adopted. The J-R curve will be expressed as a function of $A_{2}$. To ensure the transferability of the fracture toughness from the laboratory specimens to the actual waste tanks, the parameter $\mathrm{A}_{2}$ for the tank geometry will be determined by the finite element method. This project is being performed under the 20002001 SRTC Strategic Research and Development Program.

The FAD approach can also be modified to include the additional fracture parameter [3941]. It is expected that the constraint-based fracture methodologies would provide more realistic predictions of the instability crack length. Because the material resistance to cracking is higher in the less constrained configuration of a tank than in the laboratory test specimens, a longer instability crack length should be predicted.

\subsection{DISCUSSION AND CONCLUDING REMARKS}

- The finite element method provides the most accurate J-integral solution for the structural components containing flaws under service loads.

- Comparing the J-integral solution from the finite element analysis with the actual tensile property input, the CCP approximation with a curvature correction was shown to be accurate for crack length less than 30 inches and under hoop stress loading up to about $1 / 2$ of the yield stress (18 ksi) of the material.

- The predicted instability crack lengths depend on the specific FAD method.

- The FAD constructed from the finite element results (API 579 Method C Assessment) is consistent with the original FAD based on the strip yield model and the general FAD formulation in the API 579 Method A Assessment (or CEGB R6 Option 1).

- The ductile tearing FAD (API 579 Method D Assessment) is equivalent to a standard FAD approach with a constant $J_{\text {crit. }}$

- Instability crack lengths based on the FAD analysis are not always conservative with respect to the J-T analysis using estimation methods such as the CCP approximation.

- Applying a factor of safety to the actual loads with the FAD approach might lead to a 
non-conservative estimate (with respect to the J-integral estimation methods) of the instability flaw size.

- The FAD-based instability crack lengths are bounded by the results of the J-T method (specified in the API 579 Method E Assessments) with accurate finite element Jintegral solutions.

- The J-T method with an accurate finite element J-integral solution will maximize the stable crack length predicted for the waste tanks. As a result, the tank fill limit may be increased.

- The finite element analyses may encounter numerical difficulties for long cracks under severe, near yield stress loading. More accurate solutions for these extreme conditions can be achieved by customizing the finite element mesh for each crack length and by implementing finite strain analysis (geometry nonlinearity).

- The instability crack lengths calculated in this report will be compared to the predictions with crack tip constraint effect built in the fracture toughness or J-R curve when the solution is available.

\subsection{REFERENCES}

1. "Radioactive Waste Management," DOE O 435.1, U. S. Department of Energy, Washington, D. C., approved July 9, 1999.

2. "Radioactive Waste Management Manual," DOE M 435.1, U. S. Department of Energy, Washington, D. C., approved July 9, 1999.

3. "Implementation Guide for use with DOE M 435.1," DOE G 435.1, U. S. Department of Energy, Washington, D. C., approved July 9, 1999.

4. Bandyopadhyay, K., Bush, S., Kassir, M., Mather, B., Shewmon, P., Streicher, M., Thompson, B., van Rooyen, D., and Weeks, J., "Guidelines for Development of Structural Integrity Programs for DOE High-Level Waste Storage Tanks," BNL-52527, prepared by the Engineering Research and Applications Division, Brookhaven National Laboratory, Associated Universities, Inc. for the Office of Environmental Restoration and Waste Management, January 1997.

5. Sindelar, R. L. and Wiersma, B. J., "Fracture Characterization and Toughness of ASTM A285 Carbon Steel for Types I and II Waste Tanks," WSRC-TR-94-038, Westinghouse Savannah River Company, Aiken, SC, February 1994.

6. “Technical Standards: Waste Tank Farms,” DPSTS-241-7.01, March 1977.

7. "Fitness-for-Service API Recommended Practice 579 First Edition," American Petroleum Institute, API Publishing Services, Washington, D. C., January 2000.

8. Milne, I, Ainsworth, R. A., Dowling, A. R., and Stewart, A. T., "Assessment of the Integrity of Structures Containing Defects," Central Electricity Generating Board Report R/H/R6-Rev. 3, May 1986; Also in International Journal of Pressure Vessel \& Piping, Vol. 32, pp. 3-104, 1988.

9. Subramanian, K. H. and Duncan, A. J., "Tensile Properties for Application to Type I and Type II Waste Tank Flaw Stability Analysis (U)," WSRC-TR-200000232, Westinghouse Savannah River Company, Aiken, SC, July 2000.

10. Subramanian, K. H. Duncan, A. J. and Sindelar, R. L., "Mechanical Properties for Application to Type I and Type II Waste Tank Flaw Stability Analysis (U)," 
WSRC-TR-99-00416 Rev. 1, Westinghouse Savannah River Company, Aiken, SC, October 2000.

11. Shih, C.F. and Hutchinson, J.W., "Fully Plastic Solutions and Large Scale Yielding Estimates for Plane Stress Crack Problems," Trans. American Society of Mechanical Engineers, Journal of Engineering Materials and Technology, Series H, Vol. 98, pp. 289-295, 1976.

12. Lam, P. S. and Sindelar, R. L., "J-Integral Based Flaw Stability Analysis of Mild Steel Storage Tanks," in Fracture, Fatigue and Weld Residual Stress, J. Pan, Ed., American Society of Mechanical Engineers, PVP-Vol. 393, pp. 139-143, 1999.

13. Lam, P. S. and Sindelar R. L., "Flaw Stability in Mild Steel Tanks in the UpperShelf Ductile Range - Part II: J-Integral Based Fracture Analysis," ASME Journal of Pressure Vessel Technology, Vol. 122, pp. 169-173, May 2000.

14. Lam, P. S. and Sindelar, R. L., "Preliminary Report - Type I Waste Tank Flaw Stability Analysis and Tank Fill Limits (U)," WSRC-TR-99-00163, Westinghouse Savannah River Company, Aiken, SC, May 1999.

15. Mehta, H.S., "Fracture Mechanics Evaluation of Potential Flaw Indications in the Savannah River L, P and K Tanks," SASR\#86-64 (DRF137-0010), General Electric Nuclear Energy, San Jose, CA, October 1989.

16. Anderson, T. L., Fracture Mechanics: Fundamentals and Applications, $2^{\text {nd }}$ Edition, CRC Press, Boca Raton, Florida, 1995.

17. Stoner, K, J., Sindelar, R. L., and Caskey, Jr., G. R., "Reactor Materials Program - Baseline Material Property Handbook - Mechanical Properties of 1950' Vintage Stainless Steel Weldment Components (U)," WSRC-TR-91-10, Westinghouse Savannah River Company, Aiken, SC, April 1991.

18. Lam, P. S., Sindelar, R. L.," Heat Exchanger Head and Shell Acceptance Criteria," WSRC-TR-92-425, Westinghouse Savannah River Company, Aiken, SC, September 1992.

19. Lam, P. S., Sindelar, R. L., and Awadalla, N.G., "Acceptance Criteria for Inservice Inspection of Heat Exchanger Head and Shell Components," in Fatigue and Fracture of Aerospace Structural Materials, A. Nagar and A.-Y. Kuo, Eds., American Society of Mechanical Engineers, AD-Vol. 36, pp. 43-57, 1993.

20. Erdogan, F., "Theoretical and Experimental Study of Fracture in Pipelines Containing Circumferential Flaws," DOT-RSPA-DMA-50/83/3, Department of Mechanical Engineering and Mechanics, Lehigh University, Bethlehem, PA, prepared for US Department of Transportation, August 1982.

21. Rooke, D. P., and Cartwright, D. J., Compendium of Stress Intensity Factors, Her Majesty's Stationery Office, London, 1976.

22. Tada, H., Paris, P.C. and Irwin, G.R., The Stress Analysis of Cracks Handbook, Second Edition, Pages 33.3, 33.4, 33.6 and 34.1, Paris Productions Incorporated (and Del Research Corporation), Saint Louis, MO, 1985.

23. Green, D. and Knowles, J., "The Treatment of Residual Stress in Fracture Assessment of Pressure Vessels," Journal of Pressure Vessels Technology, Vol. 116, pp. 345-352, 1994.

24. Dong, P., Zhang, J., Hong, J. K., and Brust, F. W., "Task 1: Residual Stresses and Stress Intensity Factors for Single Butt Welds," Final Report No. G003824-01, Battelle Memorial Institute, Columbus, OH 43201, September 1999. 
25. Dong, P., Zhang, J., Hong, J. K., and Brust, F. W., "Task 2: Residual Stresses and Stress Intensity Factors for Intersecting Horizontal and Vertical Welds," Final Report No. G003824-02, Battelle Memorial Institute, Columbus, OH 43201, November 1999.

26. Dong, P., Zhang, J., Hong, J. K., and Brust, F. W., "Task 3: Residual Stresses and Stress Intensity Factors for Weld Repairs and Attachments," Final Report No. G003824-03, Battelle Memorial Institute, Columbus, OH 43201, February 29, 2000.

27. Dugdale, D. S., "Yielding of Steels Containing Slits," Journal of Mechanics and Physics of Solids, Vol. 8, pp. 100-108, 1960.

28. Kumar, V., German, M. D., and Shih, C. F., "An Engineering Approach for Elastic-Plastic Fracture Analysis," EPRI Topical report NP-1931, Electric Power Research Institute, Palo Alto, California, July 1981

29. Shih, C. F., Kumar, V., and German, M. D., "Studies on the Failure Assessment Diagram Using the Estimation Method and J-Controlled Crack Growth Approach," in Elastic-Plastic Fracture, Second Symposium, Vol. II, ASTM STP 803, C. F. Shih and J. P. Gudas, Eds., American Society for Testing and Materials, pp. II-239-II-261, 1983.

30. Wiersma, B. J. to Lewis, B. L., "Peer Review III of Life Management Program," Interoffice Memorandum HLW-STE-2000-0144, Westinghouse Savannah River Company, Aiken, SC, March 23, 2000 (Attachment by Anderson, T. L., Saxena, A., and Sims, J. R., "High-level Waste Tank Integrity Peer Review: Mechanical Properties of Steels Used for Type I and II Waste Tanks," January 18, 2000).

31. ABAQUS/Standard, Version 5.8, Hibbitt, Karlsson \& Sorensen, Inc., Pawtucket, Rhode Island, 1998.

32. Scott, P. M., Anderson, T. L., Osage, D. A., and Wilkowski, G. M., "Review of Existing Fitness-for-Service Criteria for Crack-Like Flaws,” WRC Bulletin 430, Welding Research Council, Inc., New York, April 1988.

33. Gong, C., "Validation of ABAQUS Finite Element Software for structural Analysis at the Savannah River Site," G-VVR-G-00007, Rev. 1, Engineering Development Section, Westinghouse Savannah River Company, Aiken, SC, August 1999.

34. Chao, Y. J., Zhu, X. K., Lam, P.-S., Louthan, M. R., and Iyer, N. C., “Application of the Two-Parameter J-A 2 Description to Ductile Crack Growth," in Fatigue and Fracture Mechanics: $31^{\text {st }}$ Volume, ASTM STP 1389, G. R. Halford and J. P. Gallagher, Eds., American Society for Testing and Materials, West Conshohocken, PA, pp. 165-182, 2000.

35. Yang, S., Chao, Y. J. and Sutton, M. A., "Higher order asymptotic crack tip fields in a power-law hardening material," Engineering Fracture Mechanics, Vol. 45, pp. 1-20, 1993.

36. Yang, S., Chao, Y. J. and Sutton, M. A., "Complete Theoretical Analysis for 70

37. Higher Order Asymptotic Terms and the HRR Zone at a Crack Tip for Mode I and Mode II Loading of a Hardening Material," Acta Mechanica, Vol. 98, pp. 7998, 1993.

38. Chao, Y. J., Yang, S. and Sutton, M. A., "On The Fracture of Solids Characterized by One or Two Parameters: Theory and Practice," Journal of the 
Mechanics and Physics of Solids, Vol. 42, pp. 629-647, 1994.

39. Joyce, J. A. and Link, R. E., "Application of two parameter elastic-plastic fracture mechanics to analysis of structures," Engineering Fracture Mechanics, Vol. 57, pp. 431-446, 1997.

40. MacLennan, I. J. and Hancock, J. W., "Constraint-based Failure Assessment Diagrams," Proceedings Royal Society of London, Series A, Vol. 451, pp. 757777, 1995.

41. Hancock, J. W. and Kekal, A., "The Application of Constraint Based Fracture Mechanics to Engineering Structures," Nuclear Engineering and Design, Vol. 184, pp. 77-88, 1998.

42. Ainsworth, R. A. and O'Dowd, N. P., "A Framework for Including Constraint Effects in the Failure Assessment Diagram Approach for Fracture Assessment," in Fracture Mechanics Applications, H. S. Mehta, Ed., American Society of Mechanical Engineers, PVP-Vol. 287/MD-Vol. 47, pp. 137-145, 1994. 



\section{REPORT WSRC-TR-2000-00478}

\section{DISTRIBUTION}

\section{SAVANNAH RIVER SITE}

S. Wood, 773-A

C. R. Wolfe, 773-A

T. J. Lex, 703-H

L. M. Papouchado, 773-A

J. P. Morin, 703-H

D. J. Green, 773-A

T. M. Monahon, 703-H

N. C. Iyer, 773-A

B. L. Lewis, 703-H

M. R. Louthan, 773-A

D. J. Martin, 703-H

R. L. Sindelar, 773-41A

B. J. Wiersma, 773-A

G. T. Chandler, 773-A

F. Loceff, 730-1B

S. L. West, 773-A

G. B. Rawls, Jr., 730-1B

P. S. Lam, 773-41A

A. J. Duncan, 773-41A

Site Records, 773-52A

K. H. Subramanian, 773-41A

M. J. Morgan, 773-A

P. E. Zapp, 773-A 